SISOMOS AMERICANOS

Revista de Estudios Transfronterizos
Volumen XXI, número 2,

Julio-diciembre de 2021.

Recibido: 15 de junio de 2021.

Aprobado: 13 de octubre de 2021.

\title{
Selectos pero desiguales: inmigrantes latinoamericanos en México (1990-2015)*
}

\section{Selected but unequal: Latin American immigrants in Mexico (1990-2015)}

\author{
Marina Ariza**
}

Instituto de Investigaciones Sociales, Universidad Nacional Autónoma de México, México.

\author{
Luis Felipe Jiménez Chaves ${ }^{* * *}$
}

Consejo Nacional de Población, México.

\section{Resumen}

Con base en técnicas estadísticas multivariadas, se analiza la heterogeneidad (sociodemográfica y sociolaboral) de la inmigración latinoamericana en México (1990-2015) como parte de los intercambios intrarregionales. Los resultados confirman el predominio femenino y la alta selectividad de los latinoamericanos residentes en México, nacidos fuera de Centroamérica, y su mejor inserción laboral en relación con el resto de los latinoamericanos y los mexicanos. El contraste entre colectivos de mayor y menor tradición migratoria al país (cubanos y argentinos; colombianos y venezolanos) revela patrones demográficos consistentes con dicha diferenciación, e importantes desigualdades internas

\footnotetext{
${ }^{*}$ Este artículo es resultado del proyecto de investigación Heterogeneidad de la inmigración latinoamericana a México: perfiles laborales y desigualdades intrarregionales, financiado por el Instituto de Investigaciones Sociales de la Universidad Nacional Autónoma de México. Agradecemos el apoyo de Damaris Del Angel en el procesamiento estadístico.

** Doctora en Ciencia Social con especialidad en Sociología, El Colegio de México, México. Socióloga, Instituto de Investigaciones Sociales de la Universidad Nacional Autónoma de México. Correo electrónico: ariza@unam.mx ORCID: 0000-0002-7359-2348

*** Demógrafo, Consejo Nacional de Población, México. Maestro en Población y Desarrollo, Facultad Latinoamericana de Ciencias Sociales, sede México. Correo electrónico: lfjimenez@ conapo.gob.mx ORCID: 0000-0001-6197-9070
}

Cómo citar este artículo: Ariza, M. y Jiménez, L. (2021). Selectos pero desiguales: inmigrantes latinoamericanos en México (1990-2015). Si Somos Americanos. Revista de Estudios Transfronterizos, 21(2), 170-202. doi: 10.4067/S0719-09482021000200170 
medidas a través del ingreso laboral, en las que inciden tanto el origen de los inmigrantes como la diversidad de los mercados de trabajo en que participan.

Palabras clave: inmigrantes latinoamericanos, heterogeneidad, desigualdad laboral.

\begin{abstract}
On the basis of multivariate statistical techniques, this article analyzes the socio-demographic and labor heterogeneity of Latin American immigration in Mexico (1990-2015) as part of intra-regional exchanges. The findings confirm the predominance of women and the high selectivity of Latin Americans born outside of Central America but residing in Mexico, and their improved economic insertion in relation to Mexicans and other Latin Americans. The contrast between groups with a greater and lesser migratory tradition to said country (Cubans and Argentineans; Colombians and Venezuelans), reveals demographic patterns consistent with this differentiation, and significant internal inequalities measured through their working income, in which both the origin of immigrants and the diversity of the labor markets in which they participate come into play.
\end{abstract}

Keywords: Latin American immigrants, heterogeneity, labor inequality.

\title{
Introducción
}

A pesar de que México figura entre los primeros cuatro países receptores de inmigrantes intrarregionales, son relativamente pocos los estudios que abordan su papel en el sistema migratorio regional; menos aun los que analizan la inserción laboral de los inmigrantes (CEPAL y OIT, 2017; Leiva, Mansilla y Comelin, 2017). Presente desde al menos las últimas décadas del siglo XIX, la inmigración latinoamericana a México ha crecido de manera sostenida desde los años setenta del pasado siglo XX, al compás de una compleja serie de procesos políticos, sociales y económicos que han propulsado la emigración desde los países de origen. Dentro de estos factores han ganado preeminencia en las últimas décadas las reiteradas crisis económicas que han azotado a varios países de la región desde la década de 1990. Omitiendo la inmigración centroamericana en virtud de la vecindad geográfica, tres son las subregiones que mayores inmigrantes han aportado al país en las últimas décadas: la región Andina (Colombia y Venezuela), el Cono Sur (Argentina) y el Caribe (Cuba). El rasgo más destacable de estos inmigrantes es su alta selectividad educativa, lo que les confiere ventajas indudables en el mercado de trabajo vis a vis el resto de los latinoamericanos y los nacidos en México.

El objetivo de este artículo es profundizar en el conocimiento de esta inmigración en un período reciente (1990-2015), al tomar en cuenta su heterogeneidad sociodemográfica y sociolaboral, examinando en su inserción económica en el mercado de trabajo. Agrupamos los cuatro colectivos más importantes de acuerdo con su mayor (cubanos, argentinos) o 
menor tradición migratoria al país (colombianos, venezolanos) ${ }^{1}$ contrastándolos de manera sistemática con el resto de los latinoamericanos. Los datos en que nos basamos provienen de los Censos de Población y Vivienda de 1990, 2000 y 2010 y de la Encuesta Intercensal 2015 (INEGI, s. f.-a, s. f.-b, s. f.-c).

El trabajo se divide en cinco apartados, además de esta introducción. En el primero se bosquejan las tendencias de la inmigración latinoamericana a México en el contexto de la dinámica migratoria regional, deteniéndonos en la caracterización de los grupos seleccionados. En el segundo se expone el concepto de selectividad migratoria delineando algunas de sus implicaciones. En el tercero se enuncian el abordaje metodológico y la estrategia analítica. El examen empírico del stock de los inmigrantes es emprendido en los apartados cuarto y quinto con el apoyo de dos técnicas estadísticas complementarias: análisis de correspondencias múltiples y análisis de regresión lineal. Las conclusiones sintetizan los principales hallazgos.

\section{Tendencias de la inmigración latinoamericana a México}

Aun cuando América Latina es una región de emigración neta, ${ }^{2}$ uno de los rasgos de su dinámica migratoria reciente es el incremento de los intercambios intrarregionales (Martínez, Cano y Soffia, 2014; Martínez y Orrego, 2016). Entre 2000 y 2010, el stock de latinoamericanos residiendo en un país de la región distinto al de su nacimiento aumentó 31,6 \% (Martínez y Orrego, 2016, p. 15). En términos absolutos, México figuraba en 2010 entre los cuatro principales destinos de estos intercambios interregionales, junto a Argentina, la República Bolivariana de Venezuela (cuya situación ha cambiado radicalmente desde entonces) y Brasil. En el lapso de 2010 a 2015, el país azteca fue-después de Chile-la nación con el mayor incremento relativo de inmigrantes latinoamericanos (CEPAL y OIT, 2017).

Son los años setenta del pasado siglo XX los que marcan el inicio de la tendencia al aumento de la inmigración regional a México. De 1970 a 2015, dicha inmigración creció a un ritmo medio anual de entre 4,1 y 4,5 \%, siendo las décadas de 1970-1980 y 2000-2010 las de mayor dinamismo relativo (ver tabla 1). Como resultado, en los 45 años transcurridos entre 1970 y 2015 el stock de latinoamericanos residentes en México se sextuplicó al pasar de 26.897 personas a 170.723. A partir de 1990, los nacidos en América Latina ocupan el segundo lugar en el total de los inmigrantes, solo después de los estadounidenses, momento en que desplazan a los europeos (principalmente españoles), cuya presencia mengua de forma sostenida de 1970 en adelante (Rodríguez, 2010).

\footnotetext{
${ }^{1}$ Por tradición migratoria entendemos la presencia histórica de estos inmigrantes en el país.

${ }^{2}$ De acuerdo con los datos censales de 2010, alrededor de 28,4 millones de latinoamericanos eran emigrantes, equivalentes al 4,8 \% de la población; en contraste, 7 millones 564 mil eran inmigrantes (extra e interregionales) (Martínez y Orrego, 2016).
} 
En realidad, gran parte de los inmigrantes estadounidenses son personas de origen mexicano, aspecto que dificulta la valoración del peso real de la inmigración (intra y extrarregional) al país. Con base en la Encuesta Intercensal de 2015 (INEGI, s. f.-d), Jiménez (2018) estima que 78,56 \% de los 739.168 estadounidenses residentes en México en 2015 son personas de origen mexicano, 89,1\% de los cuales tiene menos de 18 años; es decir, se trata de hijos de mexicanos nacidos en Estados Unidos que residen en el país de sus progenitores (menores de edad). Al excluirlos, quedan 158.474 estadounidenses, número inferior a los 170.723 latinoamericanos asentados en el país en ese mismo año, según la misma fuente de información. ${ }^{3}$ Por tanto, el ejercicio coloca a los latinoamericanos como el primer grupo de inmigración en México en 2015, realzando la importancia de los intercambios intrarregionales.

Los factores detrás del incremento de la inmigración latinoamericana a México en las últimas décadas son múltiples y su importancia relativa varía en cada momento. Por un lado, figuran las condiciones cambiantes (políticas, sociales y económicas) de los países de origen en tanto contextos de salida específicos; por el otro, el lugar de México en el sistema migratorio regional en su cuádruple condición de país de inmigración, emigración, tránsito y retorno; y antesala del principal polo de atracción de la migración a nivel mundial. Son relevantes también las implicaciones de los procesos de integración económica sobre las posibilidades de movilidad a escala regional, y las políticas migratorias en tanto inciden en la selectividad de los flujos y las posibilidades de asentamiento.

La materialización de acuerdos internacionales como parte de la constitución de bloques económicos subregionales suele conllevar la derogación de los requisitos de visado entre los países signatarios. Poco más de un año y medio después de conformada la Alianza del Pacífico entre Colombia, Perú, Chile y México, en abril de 2011, el país azteca suprimió la exigencia de visa para los ciudadanos de las dos primeras naciones, otorgándoles a partir de entonces el mismo trato que a los chilenos. ${ }^{4}$

En sentido general, las políticas migratorias mexicanas han sido altamente selectivas (Rodríguez, 2010; Yankelevich, 2011). Con excepción de la Ley de Extranjería y Naturalización de 1886, concebida para promover el arribo de inmigrantes europeos, todas las demás disposiciones legislativas destacan por su carácter restrictivo, mostrando una perenne preocupación por la elegibilidad de los extranjeros (Yankelevich, 2011). ${ }^{5}$ Así, para

\footnotetext{
${ }^{3}$ La estimación se realizó con base en las preguntas sobre nacionalidad, posesión de acta de nacimiento mexicana e identificación del padre y la madre, presentes en la Encuesta Intercensal de 2015 (Jiménez, 2018). Desafortunadamente no puede replicarse con las fuentes censales en que nos basamos porque no incluyen todas las preguntas necesarias.

${ }^{4}$ La supresión de la visa de turistas les permite permanecer en el país por 180 días, sin ejercer actividades remuneradas (Secretaría de Relaciones Exteriores. Gobierno de México, s. f.).

${ }^{5}$ Los criterios de selección de la Ley de Migración de 1926 buscaban prevenir el "peligro de descomposición social, cultural y política", la "degeneración racial". La Ley de Migración de 1930 promovía la "defensa del mestizo", restringiendo el ingreso a quienes consideraba poco asimilables al medio mexicano: sirios, libaneses, árabes, turcos, rusos, polacos, entre otros (Yankelevich, 2011; las comillas son nuestras).
} 
obtener la calidad de inmigrante, la Ley de Migración de 1926 exigía la obligatoriedad de saber leer y escribir; la de 1930 prohibía la entrada a quienes fueran trabajadores y a los que no tuvieran un capital equivalente a US\$ 3.000 (Yankelevich 2011, p. 43). La Ley de Población de 1974, considerada un "instrumento de vigilancia y control" (Bucheneau, 2001 cit. en González-Murphy y Koslowski, 2011), favorecía el ingreso de personas con salud física, mental y solvencia económica, siempre que no representaran una amenaza para el empleo de los mexicanos. En paralelo a estas disposiciones restrictivas, México ha mostrado una consistente actitud de acogida de los inmigrantes por razones políticas (Carrillo, 1979; Yankelevich, 2011), razón por la cual la legislación mexicana sobre el asilo es considerada una de las más amplias de América Latina (Gandini, Prieto y Lozano, 2019; Selee, Bolter, Muñoz-Pogossian y Hazán, enero, 2019)

Tabla 1. Volúmenes de los inmigrantes de América Latina en México (1970-2015)

\begin{tabular}{|c|c|c|c|c|c|c|}
\hline Región y país de origen & 1970 & 1980 & 1990 & 2000 & 2010 & 2015 \\
\hline Latinoamericanos & 26.897 & 40.821 & 86.117 & 78.586 & 135.967 & 170.723 \\
\hline Guatemala & 6.969 & 4.115 & 46.005 & 23.957 & 31.888 & 42.874 \\
\hline Colombia & 1.133 & 2.778 & 4.964 & 6.215 & 12.832 & 18.735 \\
\hline Venezuela & 805 & 1.940 & 1.533 & 2.823 & 10.786 & 15.664 \\
\hline Argentina & 1.585 & 5.479 & 4.635 & 6.480 & 14.171 & 14.747 \\
\hline Honduras & 942 & 1.500 & 1.997 & 3.722 & 9.980 & 14.544 \\
\hline Cuba & 4.175 & 3.767 & 2.979 & 6.647 & 11.822 & 12.768 \\
\hline El Salvador & 1.213 & 2.055 & 5.215 & 5.537 & 8.864 & 10.594 \\
\hline Perú & 804 & 2.188 & 2.973 & 3.749 & 6.870 & 5.448 \\
\hline Chile & 845 & 3.345 & 2.501 & 3.848 & 5.633 & 5.160 \\
\hline Otros suramérica & 538 & 4.901 & 4.740 & 6.504 & 11.792 & 13.930 \\
\hline Otros centroamericanos & 5.855 & 8.753 & 7.461 & 6.335 & 7.659 & 11.018 \\
\hline Caribe & & & 1.114 & 1.676 & 2.125 & 5.241 \\
\hline América* & 2.033 & & & 1.093 & 1.545 & \\
\hline Otros extranjeros & 164.287 & 227.570 & 253.592 & 412.518 & 831.937 & 834.743 \\
\hline No especificados & & 509 & 1.115 & 1.513 & 367 & 1.597 \\
\hline Total extranjeros & 191.184 & 268.900 & 340.824 & 492.617 & 968.271 & 1.007 .063 \\
\hline \multicolumn{7}{|c|}{$\begin{array}{c}\text { Tasas de crecimiento medias anuales de los latinoamericanos y de todos los extranjeros residentes en México, } \\
1970-2015\end{array}$} \\
\hline & & 1970-1980 & 1980-1990 & $1990-2000$ & $2000-2010$ & $2010-2015$ \\
\hline $\begin{array}{l}\text { Tasa de crecimiento promedio } \\
\text { anual latinoamericanos }\end{array}$ & & 4,17 & 7,47 & $-0,92$ & 5,48 & 4,55 \\
\hline $\begin{array}{l}\text { Tasa de crecimiento promedio } \\
\text { anual total }\end{array}$ & & 3,40 & 2,40 & 3,70 & 6,80 & 0,79 \\
\hline
\end{tabular}

*La información censal correspondiente a los años 1970, 1980, 1990, 2000 y 2010 en los catalogados como "América" no permite distinguir si son originarios de Estados Unidos o de América Latina.

Fuente: estimaciones propias con base en los censos de población 1990, 2000, 2010 y en la Encuesta Intercensal 2015 (Instituto Nacional de Estadística y Geografía [INEGI], s. f.-d).

Tomando como referencia 1970, década en que se inicia el incremento de la inmigración latinoamericana a México, pueden identificarse dos subperíodos según los factores que la impulsan: a) 1970-1990; y b) 1990-2015. Mientras en el primero predominan los aspectos 
políticos; en el segundo prevalecen los económicos. A estos se suma en años más recientes la violencia como detonante de la movilidad en un subconjunto de países de la región.

La irrupción del exilio latinoamericano a consecuencia de las dictaduras militares del Cono Sur, el arribo masivo de desplazados y refugiados guatemaltecos al Sureste mexicano por la prolongada guerra civil que vivió ese país entre 1960 y 1996 (Castillo y Olivera, 2010; Pederzini, Ruismena, Masferrer y Molina, 2015), ${ }^{6}$ y la llegada de colombianos y salvadoreños escapando de graves conflictos armados internos, distinguen al primer subperíodo. Consecuentemente, son los guatemaltecos, salvadoreños, colombianos, argentinos, peruanos y chilenos, los seis colectivos con un mayor incremento absoluto entre 1970 y 1990 (ver tabla 1). Con excepción de 1980, los nacidos en Guatemala han sido siempre el primer grupo de inmigración en México, dada su condición de país limítrofe, pauta que se replica en el resto de la región: el primer país de inmigración es siempre un país fronterizo (Martínez y Orrego, 2016).

Una vez restablecidas las democracias en el Cono Sur y alcanzados los acuerdos de paz en Centroamérica a principios de los noventa, adquieren relevancia los factores económicos como determinantes de la emigración a México. Las recurrentes crisis financieras que azotaron a varios países de la región, luego de los procesos de reestructuración y liberalización económica, constituyeron el caldo de cultivo de estos desplazamientos. En fechas más próximas, al abrirse paso la década de 2000, irrumpen la violencia y la profunda descomposición social e institucional como detonantes de la movilidad en un subconjunto de naciones de Centroamérica (Durand, 2020). Todo ello configura un mapa migratorio nacional denso y complejo, en el que se yuxtaponen los factores mencionados. Los inmigrantes con un mayor incremento absoluto en este segundo subperíodo (1990-2015) fueron: los argentinos, los venezolanos, los cubanos y los colombianos, países que vivieron crisis económicas de gran calado; también, los hondureños y guatemaltecos, inmersos en profundas crisis sociales.

\section{Inmigrantes latinoamericanos recientes (1990-2015)}

Cubanos, argentinos, colombianos y venezolanos, los primeros cuatro colectivos de inmigración en este subperíodo, difieren entre sí respecto de la tradición migratoria a México. Los dos primeros poseen añejas raíces; los andinos, en cambio (principalmente los venezolanos), son de menor arraigo. Al contextualizarlos, conservamos este criterio de diferenciación.

\footnotetext{
${ }^{6}$ Con base en fuentes externas, Castillo y Olivera (2010) señalan que alrededor de 46 mil guatemaltecos fueron desplazados por violencia entre 1982 y 1984, a los que habría que añadir los miles que se trasladaron por su cuenta.
} 


\section{Cubanos y argentinos}

La inmigración cubana a México es histórica, un "goteo constante y perdurable" que anida en el siglo XIX en el contexto de las guerras de independencia de Cuba (1868-1998) (Herrera, 2010). ${ }^{7}$ Las fuentes censales registran la presencia de los isleños desde 1910. De las Antillas Mayores, Cuba es la que más contacto ha tenido con México, algo que no deja de estar influido por la proximidad geográfica entre la Península de Yucatán y la isla caribeña, y por los importantes vínculos económicos tejidos en perspectiva histórica entre los terratenientes cubanos y los hacendados de Yucatán, Veracruz y Oaxaca (Herrera, 2010; Martínez y Bobes, 2010; Palma, 2006; Salazar, 2010).

Desde 1930, Cuba ha registrado saldos migratorios negativos, con un incremento sustancial de 1959 en adelante (Aja, Rodríguez, Orosa y Albizu-Campos, 2017). Si bien solo 5\% de esta emigración tiene como destino América Latina, México figura entre los países preferidos, junto a Venezuela, República Dominicana, Costa Rica, Ecuador, Chile y Brasil (Aja et al., 2017). La inmigración cubana a México ha crecido sostenidamente desde 1960 (con la única excepción del año 1990), con sendos picos en los períodos intercensales de 1990-2010 y 2000-2010 (ver gráfico 1). Estos guardan relación con la profunda crisis que vivió el país a raíz del desmembramiento de la Unión de Repúblicas Socialistas Soviéticas (URSS). El llamado Período Especial en Tiempo de Paz, la estrategia con la que el gobierno cubano enfrentó la coyuntura, se inició con una exorbitante contracción del PIB del orden del $37,2 \%$, de consecuencias catastróficas para los niveles de vida de la población y que trajo amplias secuelas colaterales (Martínez, 2016) .

Una parte de la inmigración cubana reciente a México es en realidad migración de tránsito. El anuncio del restablecimiento de las relaciones diplomáticas con la isla, hecho por Barack Obama en diciembre de 2014, parece haber exacerbado este componente en su universo ante el temor que suscitó en los isleños la eventual pérdida del trato preferencial del que gozaron históricamente (Ramírez, 2019; Martínez, 2016) .

En contraste, no es sino hasta 1970 cuando gana presencia la inmigración argentina a México. De acuerdo con Yankelevich (2010), previo al golpe de Estado de Jorge Videla, en 1976, la emigración argentina a México era irrelevante. De 1970 a 2015 se verifican dos incrementos intercensales de importancia: 1) 1970-1980, momento en que se triplican; 2) 2000-2010, cuando pasan de 6.480 a 14.171; es decir, se duplican (ver gráfico 1). A diferencia de la inmigración política de los años setenta, la gran afluencia de argentinos a partir del 2000 forma parte del llamado "exilio económico" que emprendieron miles de estos nacionales

\footnotetext{
${ }^{7}$ En la perdurabilidad de este flujo debe tomarse en cuenta que México fue el único país de América Latina que no puso fin a las relaciones diplomáticas con Cuba luego de su expulsión de la OEA, en 1964.

${ }^{8}$ Cabe mencionar la orden ejecutiva Pies secos/Pies mojados, de 1995, que les otorgaba permanencia legal y eventual acceso a la residencia, siempre que no fueran interceptados en alta mar ("pies mojados"). Con base en Cancio (5 de enero de 2015), Ramírez (2019, p. 122), se documenta la llegada en 2014 de 16.247 cubanos a territorio estadounidense por la frontera mexicana.
} 


\section{Gráfico 1. Volúmenes de los inmigrantes latinoamericanos en México}

(países seleccionados: 1970-2015)

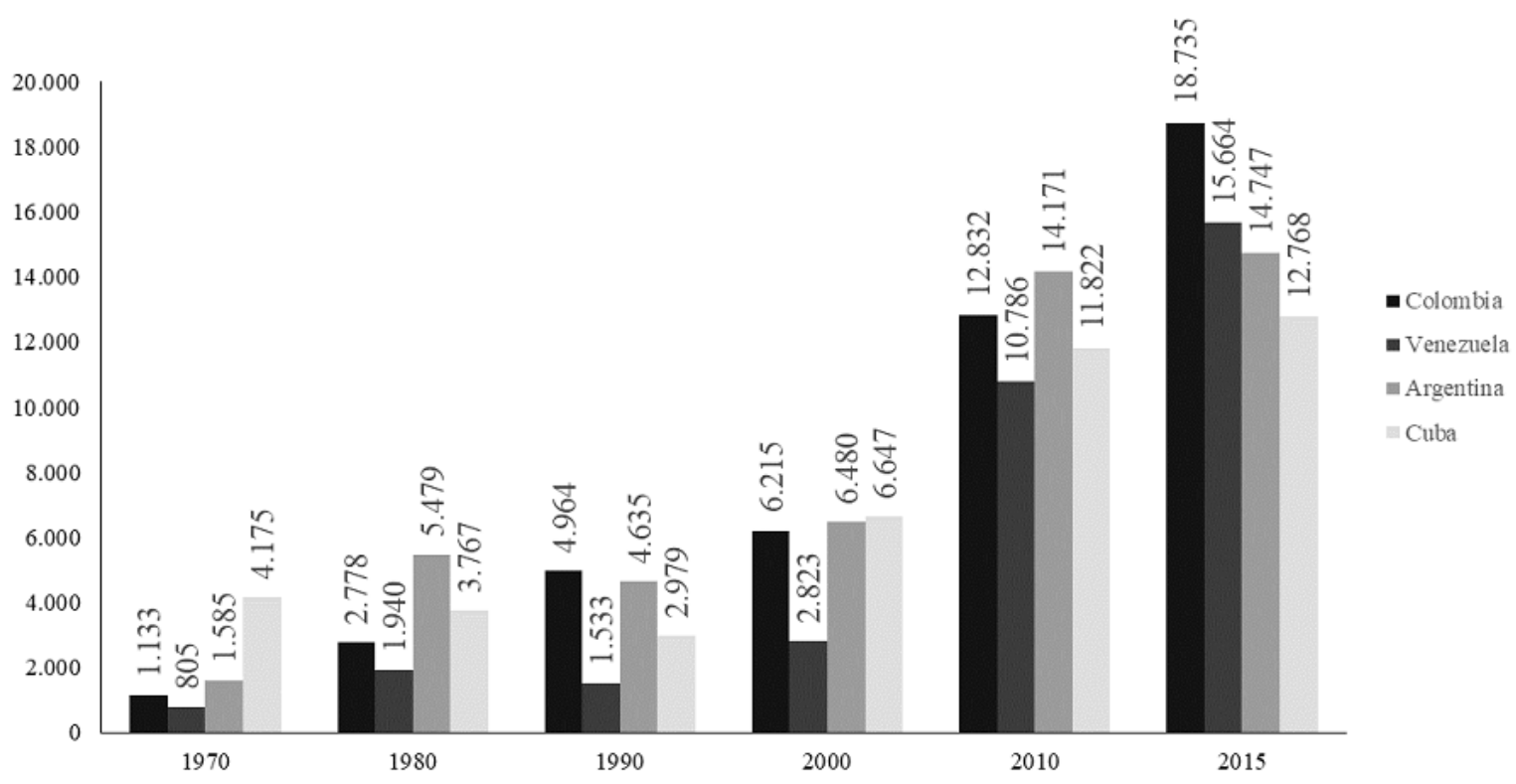

Fuente: estimaciones propias con base en los censos de población 1990, 2000, 2010 y en la Encuesta Intercensal 2015 (INEGI, s. f.-d).

luego de la explosiva crisis que sacudió al país al colapsar el modelo económico instaurado a principios de los noventa, el llamado Plan de Convertibilidad, de consecuencias catastróficas. Dos de los rasgos emblemáticos de esta emigración fueron su volumen y su vertiginosidad (Esteban, 2003; Gandini, 2015). Se estima que tan solo entre 2000 y 2001 abandonaron el país 118.087 personas, monto equivalente a la emigración de diez años (Esteban, 2003, p. 32). Fue también la primera vez que se registraron saldos migratorios negativos.

En términos analíticos, el evento supuso una inversión del rol jugado hasta entonces por el país rioplatense en el contexto regional: de receptor de población a expulsor (Esteban, 2003; Solimano, 2003), hecho que se revertiría posteriormente. ${ }^{9}$ A raíz de la crisis económica de principios del siglo XX, España se convirtió en el primer lugar de destino de los argentinos, desplazando a Estados Unidos, país que ante la vertiginosidad del flujo impuso en 2002 el requisito de visas. En el contexto de América Latina, México era en 2005 el séptimo país de residencia de sus emigrantes, luego de Paraguay, Chile, Bolivia, Brasil, Uruguay y Venezuela (Ratha y Shaw, 2007).

\footnotetext{
${ }^{9}$ Luego volvió a ser uno de los principales polos de inmigración regional (CEPAL y OIT, 2017).
} 


\section{Colombianos y venezolanos}

Colombia sobresale por ser uno de los países con más altos niveles de emigración en el ámbito regional, con un $10 \%$ de su población residiendo fuera en 2009 (Ramírez, Zuluaga y Perilla, 2010). Las estimaciones del Departamento Administrativo Nacional de Estadística de Colombia documentan saldos netos migratorios negativos, cada año, de 1985 a 2005 (Ramírez et al., 2010), emigración que en los últimos años no ha dejado de crecer y diversificarse (CEPAL y OIT, 2017; Neira, 2010; Polo y Serrano, 2019).

La inmigración colombiana a México adquiere notoriedad a partir de 1980. Llama la atención el quinquenio 2010-2015, cuando los colombianos pasaron de 12.832 a 18.735 (ver tabla 1), constituyendo en 2015 el grupo más numeroso de latinoamericanos residiendo en el país (con excepción de los guatemaltecos). En el ámbito regional, México figura en la quinta posición entre los destinos de sus emigrantes (Ratha y Shaw, 2007); Estados Unidos y España son sus principales receptores extrarregionales.

Si bien las causas detrás de la emigración colombiana son múltiples, desde las condiciones de inseguridad hasta el deterioro del contexto sociopolítico, pasando por la ausencia de oportunidades (económicas y educativas) para amplios sectores de la población (Bermúdez, 2019), sobresalen en las últimas décadas los factores económicos (Polo y Serrano, 2019; Ramírez et al., 2010), con un parteaguas en la severa crisis financiera que atravesó el país a finales del siglo XX, una de las más agudas de su historia (Torres, 2011). ${ }^{10}$

La llegada de Hugo Chávez al poder en 1999 marca el principio de la emigración venezolana reciente, país que durante muchos años fue un polo de atracción importante de la migración intrarregional. ${ }^{11} \mathrm{El}$ fin del crecimiento económico impulsado por el boom de las materias primas, en 2012, junto a la profunda recesión y la exorbitante hiperinflación que le sucedieron, catapultaron la movilidad internacional. ${ }^{12}$ A partir de 2015 la emigración se torna masiva, una parte de la cual adquiere tintes de desplazamiento forzado en un contexto de crisis humanitaria y exacerbación de la pobreza (Acosta, Blouin y Freier, 2019; Freitez, 2019; Gandini et al., 2019; Vivas y Páez, 2017). La Organización Internacional para las Migraciones (OIM) estimó que en octubre de 2019 más de 4,4 millones de venezolanos había abandonado el país, de un universo de 28,5 (OIM, 2019), equivalente al 15,4 \% de la población; la mayoría se dirigía al Corredor Andino $^{13}$ (OIM, 2019). Es entre 2000 y 2010 cuando arriban grandes contingentes de venezolanos a México, lapso en el que estuvieron cerca de cuadruplicarse (de 2.823 a 10.786). En 2015 eran ya el segundo grupo de inmigración entre los no centroamericanos, después de los colombianos.

\footnotetext{
${ }^{10}$ En 1999, el PIB se contrajo 4,2 \%, y el desempleo escaló a $22 \%$ (Torres, 2011).

${ }^{11}$ Desde 1950, Venezuela recibió cuantiosos volúmenes de inmigrantes, con un pico en la década de 1980, superando el millón de personas (Martínez y Orrego, 2016).

${ }^{12}$ Entre 1991 y 2015, el PIB per cápita cayó 53 \%; de 2013 a 2017, la inflación acumulada fue de $10.630 \%$ (Zambrano y Sosa, 2018 cit. en Freitez, 2019).

${ }^{13}$ Ecuador, Bolivia, Colombia y Perú.
} 


\section{Selectividad de la migración e inserción laboral}

Los migrantes no constituyen una muestra representativa (aleatoria) de las sociedades de las que parten, pues poseen rasgos seleccionados -positivos o negativos- respecto del conjunto, una de las regularidades empíricas más conocidas de la migración. La edad, la escolaridad, las diferencias en la distribución de ingreso y de dispersión salarial entre las sociedades de origen y destino, la distancia geográfica, las redes sociales y las políticas migratorias, figuran entre los factores que inciden en el tipo de selectividad de los migrantes en un momento dado (Borjas, 1987; Browning y Feindt, 1969; Fernández-Huertas, 2011; Mackenzie y Rapoport, 2010).

Edad, escolaridad y sexo son los tres atributos más importantes respecto de los cuales los migrantes presentan diferencias. En general, quienes se desplazan tienden a ser personas jóvenes en edades activas en virtud de la fuerte asociación entre la movilidad espacial y la inserción laboral. Los migrantes suelen contar con niveles de escolaridad más elevados que sus pares en el lugar de origen (selección positiva) -condición menos universal que la concentración en ciertos tramos de edad-, aspecto que puede modificarse con el tiempo (Browning y Feindt, 1969). La selectividad educativa decrece a medida que en una comunidad se expanden las redes migratorias, pues estas reducen los costos de los desplazamientos, haciendo accesible la posibilidad de emigrar a un grupo más heterogéneo (menos selecto) de personas (Mackenzie y Rapoport, 2010).

El predominio masculino, femenino, o el carácter equilibrado en la composición por sexo de los flujos y los stocks de migrantes varía históricamente y es contingente a un complejo conjunto de factores difíciles de deslindar, sujetos a evaluación empírica. Cabe mencionar los aspectos estrictamente económicos (segregación por sexo de los mercados de trabajo); políticos (disposiciones que favorecen o no la reunificación familiar); y demográficos (desbalances en los mercados matrimoniales, envejecimiento demográfico, etc.).

En virtud de los objetivos analíticos de este artículo interesa destacar la importancia de la selectividad educativa por sus conocidos efectos sobre la inserción laboral de los migrantes y sus ingresos. En sí misma, la elevada escolaridad se asocia con la movilidad espacial, pues las personas más educadas son más proclives a cambiar de residencia: a mayor nivel de instrucción, mayor número de movimientos (Docquier y Marfouk, 2006; González, Recaño y López, 2020; Sjaastad, 1962). Un hallazgo generalizado es que los niveles educativos (y las habilidades y experiencia) de los migrantes favorecen sus posibilidades de inserción laboral y sus ingresos (Belot y Hatton, 2008). No obstante, dicha correlación positiva puede modificarse con el tiempo. Evidencias para Estados Unidos muestran que las discrepancias iniciales entre los ingresos de nativos e inmigrantes con niveles educativos semejantes, al momento del arribo, se atenúan con el tiempo y puedan llegar incluso a invertirse en favor de los nacidos fuera (Borjas, 1987). 
En el contexto de los países de la Organización para la Cooperación y el Desarrollo Económicos (OCDE), México destaca por ser uno de los cuatro destinos con mayores porcentajes de inmigrantes con educación terciaria, ${ }^{14}$ después de Irlanda, Canadá y Australia (valores de 39,7, 38,0, 37,9 y 37,1\%, respectivamente, datos para 2000-2001) (Belot y Hatton, 2008). El dato resulta llamativo porque -en contraste con esos países- México no es un gran receptor de migrantes. Los autores señalan que estos países (incluido México), "tienden" a seleccionar, a atraer, inmigrantes con altos niveles de escolaridad.

Datos referidos a los porcentajes de población de 25 años y más con al menos educación secundaria en los cuatro grupos de inmigrantes, respecto de la misma población en sus países de origen, corroboran la afirmación: en todos los casos los inmigrantes residentes en México exceden a sus pares en valores que oscilan entre 12,3 y 46,4 puntos porcentuales (ver tabla A.1 del Apéndice).

\section{Abordaje metodológico y estrategia analítica}

El ejercicio empírico que emprendemos a continuación persigue destacar las diferencias en la composición demográfica (nivel de feminización, escolaridad, edad, ubicación socioespacial) y la inserción económica (sector de ocupación, rama de actividad, posición en el trabajo, ingreso laboral) de los inmigrantes, destacando las desigualdades en su universo medidas según su ingreso laboral.

$\mathrm{Al}$ abordar los aspectos sociodemográficos ofrecemos una mirada panorámica con base en los Censos de Población y Vivienda de 1990, 2000 y 2010 y en la Encuesta Intercensal de 2015 (INEGI, s. f.-d). En cambio, al profundizar en la dimensión sociolaboral nos centramos en el año 2015, explotando dicha encuesta, dadas las limitaciones de los censos de población para analizar los mercados de trabajo. ${ }^{15}$ En distintos momentos del análisis introducimos como variables de control las siguientes subpoblaciones: el resto de los inmigrantes latinoamericanos, el total de los extranjeros y los nacidos en México.

El ejercicio cuantitativo se vale de análisis descriptivos y multivariados (análisis de correspondencia múltiple y regresión lineal). El análisis de correspondencias múltiple es una técnica idónea para el examen de variables categóricas, puesto que proporciona una representación gráfica de la asociación existente entre individuos y variables en un plano de dos dimensiones. Con ella perseguimos identificar los patrones de asociación existentes entre

\footnotetext{
${ }^{14}$ Porcentaje de nacidos fuera, de 15 años de edad y más, que cuenta con alguna educación terciaria (postsecundaria) (Belot y Hatton, 2008).

${ }^{15}$ En general, los censos restringen el análisis exhaustivo de la inserción laboral por el menor número de preguntas. El tamaño de la muestra de la Encuesta Intercensal 2015 (22 millones, equivalentes al $18 \%$ de una población estimada de 119 millones en 2015) permite mayores niveles de desagregación en poblaciones reducidas como estas (los inmigrantes representan menos del $1 \%$ de la población); intervalos de confianza más robustos y coeficientes de variación en los límites de representatividad confiables. Las muestras de los censos 2010 y 2020 son de menor tamaño.
} 
las variables sociolaborales y los países de origen de los inmigrantes latinoamericanos. Con la regresión lineal múltiple procuramos determinar los factores que inciden en el incremento de los ingresos laborales, controlando por un conjunto de variables independientes (individuales, sociales, laborales y espaciales, que se explicitan más adelante). Por razones estadísticas, al examinar la heterogeneidad sociolaboral (análisis de correspondencias) y los determinantes del ingreso individual (regresión lineal), excluimos a los mexicanos, pues su magnitud impediría observar las diferencias internas entre los grupos seleccionados.

La estrategia analítica plantea el contraste sistemático entre los colectivos de mayor y menor tradición migratoria a México bajo el supuesto teórico de que la antiguiedad favorece una mejor inserción laboral, ya que las desventajas iniciales de los inmigrantes (inexperiencia, desconocimiento del mercado, barreras institucionales, etc.) se reducen, a la vez que crece su capital social (redes sociales). Para algunos autores esto puede ser producto del proceso de asimilación, o de un cambio en la composición (la calidad) de las cohortes de inmigrantes (Borjas, 1987).

Así, la primera hipótesis de investigación sostiene que en un universo altamente selecto como el que conforman estos cuatro colectivos (cubanos, argentinos, colombianos y venezolanos), la mayor antigüedad promueve una mejor inserción laboral. No obstante, ello estará condicionado por la heterogeneidad socioespacial de los mercados de trabajo en que participan: a mayor concentración en las áreas metropolitanas, mejor situación laboral (segunda hipótesis). Esta es la manera en que empíricamente nos acercamos a la diversidad de los mercados de trabajo, dadas las posibilidades de desagregación que nos permite la fuente para un universo poblacional reducido como el que comprenden estos inmigrantes. Abordamos primero la dimensión sociodemográfica (nivel de feminización, escolaridad, edad, ubicación socioespacial), seguida de la laboral.

\section{Perfil sociodemográfico: selectos y heterogéneos}

Las relaciones de masculinidad (gráfico 2) muestran que las mujeres predominan entre los nacidos en América Latina: en 2015 residían en el país 90 hombres por cada 100 mujeres provenientes del subcontinente. La feminización es un aspecto general de la inmigración intrarregional (Martínez y Orrego, 2016) que halla en el caso de México una constatación más. Nuestros grupos de análisis se oponen llamativamente en este aspecto: en los cubanos y argentinos prevalecen los hombres, en los colombianos y venezolanos, las mujeres. La relativa masculinización de los cubanos y los argentinos es coherente con el perfil de sus emigrantes en los censos de 2000 y 2010, de acuerdo con la CEPAL (Martínez y Orrego, 2016). El stock de los argentinos residentes en México ha fluctuado entre el equilibrio y la masculinización (gráfico 2). Los cubanos, en cambio, transitaron de la feminización (1990- 
2010) a la masculinización. ${ }^{16}$ Es posible que esta reversión de la tendencia sea coyuntural y guarde relación con el aumento de los migrantes de tránsito en su universo, según hemos referido (Ramírez, 2019).

La feminización de los colombianos y venezolanos también es consistente con el perfil de sus emigrantes en los censos de 2000 y 2010 (Martínez y Orrego, 2016), aunque es bastante más marcada en los residentes en México, con razones de masculinidad de 73,9 y 77,9, respectivamente. En el nivel regional, los valores oscilaban entre 90 y 93,8 hombres por cada 100 mujeres en 2000 y 2010 (Martínez y Orrego, 2016, p. 19). El gráfico 2 indica que la feminización ha sido un rasgo perdurable de los inmigrantes venezolanos y colombianos en el país (Gandini, Pietro y Lozano, 2019; Merchan y Merchan, 2019).

\section{Gráfico 2. Razones de masculinidad de los inmigrantes de América Latina en México (países seleccionados: 1970-2015)}

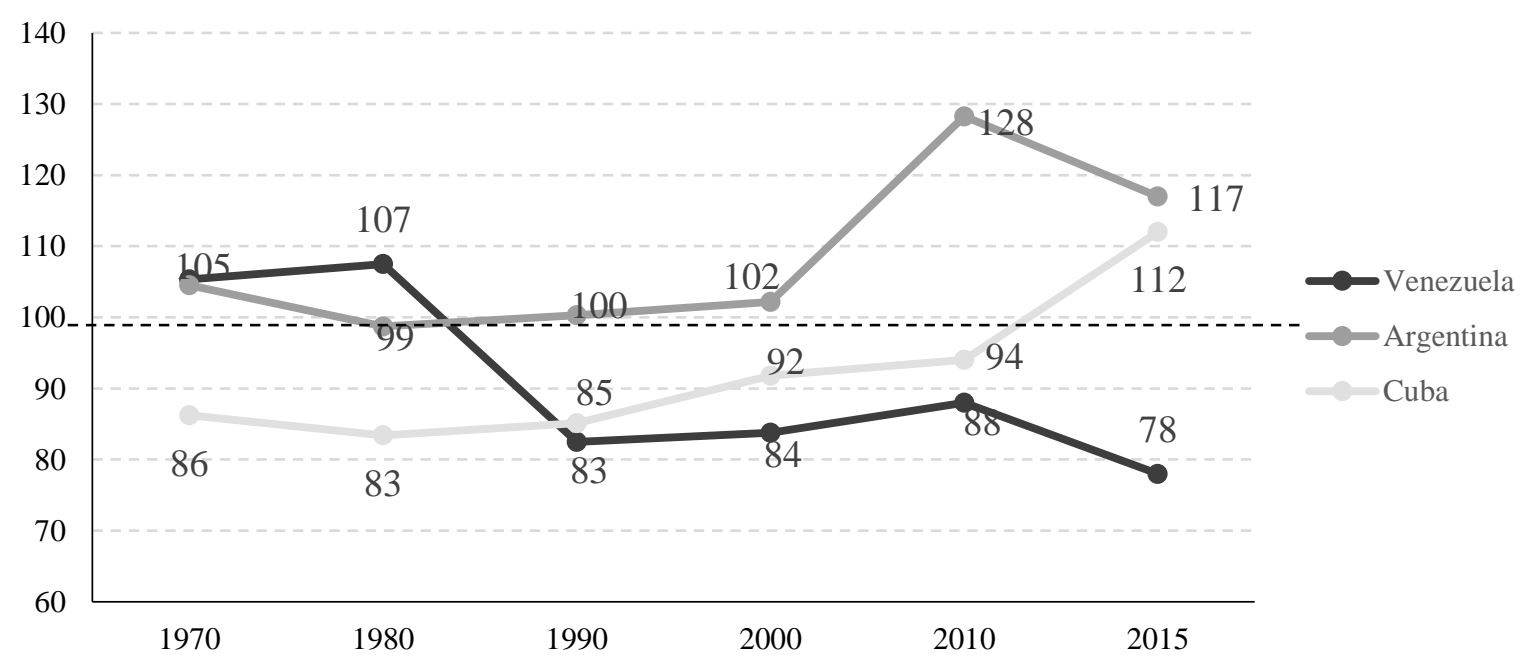

Fuente: estimaciones propias con base en los censos de población 1990, 2000, 2010 y en la Encuesta Intercensal 2015 (INEGI, s. f.-d).

En consonancia con las tendencias del cambio demográfico, la edad mediana de los inmigrantes se ha elevado de forma notable entre 1990 y 2015 (de 27 años a 36) (ver tabla 2). Los grupos de análisis difieren también respecto a este atributo: en 2015, venezolanos y colombianos eran adultos jóvenes (edad mediana de 34 y 35 años, respectivamente) e inmigrantes recientes, pues cerca de un $40 \%$ vivía cinco años atrás en otro país (ver tabla A.2 del Apéndice); en cambio, argentinos y cubanos contaban con una estructura por edad más envejecida (edad mediana de 39 y 45 años), y más de dos terceras partes (72 \%) residía en el país cinco años atrás (ver tabla A.2 del Apéndice). Tales rasgos obedecen tanto a la

\footnotetext{
${ }^{16}$ La composición por sexo de la inmigración cubana ha variado históricamente: masculinizada entre 1868 y 1959, equilibrada a mediados del siglo XX, feminizada de 1970 a 2010 (Herrera, 2010; Martínez y Bobes, 2010; y tabulaciones propias).
} 
historicidad de su inmigración a México, como al hecho de provenir de países ubicados en etapas más avanzadas del proceso de transición demográfica. ${ }^{17}$

Tabla 2. Características sociodemográficas de los inmigrantes en México (1990-2015)

\begin{tabular}{lrrrrr}
\hline & & $\mathbf{1 9 9 0}$ & $\mathbf{2 0 0 0}$ & $\mathbf{2 0 1 0}$ & $\mathbf{2 0 1 5}$ \\
\hline Edad mediana & & & & & \\
& Latinoamericanos & 27 & 34 & 35 & 36 \\
Argentina & 38 & 40 & 38 & 39 \\
Colombia & 30 & 35 & 36 & 35 \\
Cuba & 52 & 40 & 42 & 45 \\
Venezuela & 28 & 31 & 33 & 34 \\
Escolaridad media* & 25 & 32 & 35 & 35 \\
& 15 & 10 & 9 & 12 \\
& Resto de latinoamericanos & 14 & 12 & 14 \\
Otros países & & & & \\
Total extranjeros & 19 & 10,6 & 11,8 & 12,2 \\
& & & 14,1 & 15,0 & 15,0 \\
Latinoamericanos & 11,0 & 14,9 & 15,6 & 15,4 \\
Argentina & 13,4 & 13,9 & 14,7 & 15,0 \\
Colombia & 14,1 & 14,9 & 15,5 & 15,8 \\
Cuba & 12,4 & 9,2 & 9,9 & 11,5 \\
Venezuela & 14,0 & 11,9 & 12,9 & 14,2 \\
& 10,2 & 11,5 & 12,5 & 12,6 \\
\hline
\end{tabular}

*Refiere a la población de 20 años y más.

Nota: no se consideran aquellos cuyo lugar de nacimiento es catalogado como "América", porque no se puede identificar si son de Estados Unidos o de América Latina.

Fuente: estimaciones propias con base en los Censos de Población 1990, 2000, 2010 y en la Encuesta Intercensal 2015 (INEGI, s. f.-d).

Entre 1990 y 2015 se ha verificado un aumento gradual de la escolaridad media (de 11 a 12,2 años) en el total de los latinoamericanos residentes en México con 20 años y más, coherente con la ampliación del proceso de escolarización en la región (tabla 2). Los grupos de análisis presentan diferencias de acuerdo con esta variable: colombianos y venezolanos, de menor tradición migratoria al país y más jóvenes, exceden entre 0,4 y 1,1 años de escolaridad a los argentinos y cubanos a lo largo del período de observación. En 2015, los nacionales de estos países aventajaban al resto de los latinoamericanos y al total de extranjeros en al menos 2,4 años de escolaridad media.

La ubicación socioespacial, variable que nos acerca indirectamente a la diversidad de los mercados de trabajo, revela la alta concentración de los inmigrantes de esos cuatro países en las principales áreas metropolitanas del país (gráficos 3 y 4). Respecto de esta característica, los grupos de análisis no se alinean en función de la tradición migratoria: mientras los

\footnotetext{
${ }^{17}$ Cuba es el país más envejecido, con 22,9 \% de la población en el tramo de edad de 60 años y más, seguido
} de Argentina (17,8 \%), Colombia (12,1\%) y Venezuela (10,6 \%) (Naciones Unidas, 2015). 
argentinos $(62,6 \%)$ y los colombianos $(58,7 \%)$ se concentran relativamente más en la capital o en alguna de las tres metrópolis que le siguen en tamaño (Guadalajara, Monterrey, Puebla), los venezolanos, y ante todo los cubanos, se aglomeran más en términos relativos en el resto de las zonas metropolitanas, con porcentajes de 34,1 y 46,1\%, respectivamente. La presencia de los venezolanos en el resto de las áreas metropolitanas puede probablemente vincularse con la región económico funcional de Villahermosa (zona petrolera), como polo de atracción de la emigración venezolana calificada (Delgado, 2019). La dispersión espacial de los cubanos es consistente con las pautas históricas de asentamiento de sus inmigrantes en ciertas regiones del país (Península de Yucatán, Veracruz), según hemos referido anteriormente.

\section{Gráfico 3. Residencia de los inmigrantes latinoamericanos}

según área metropolitana (países seleccionados: 1990-2015)

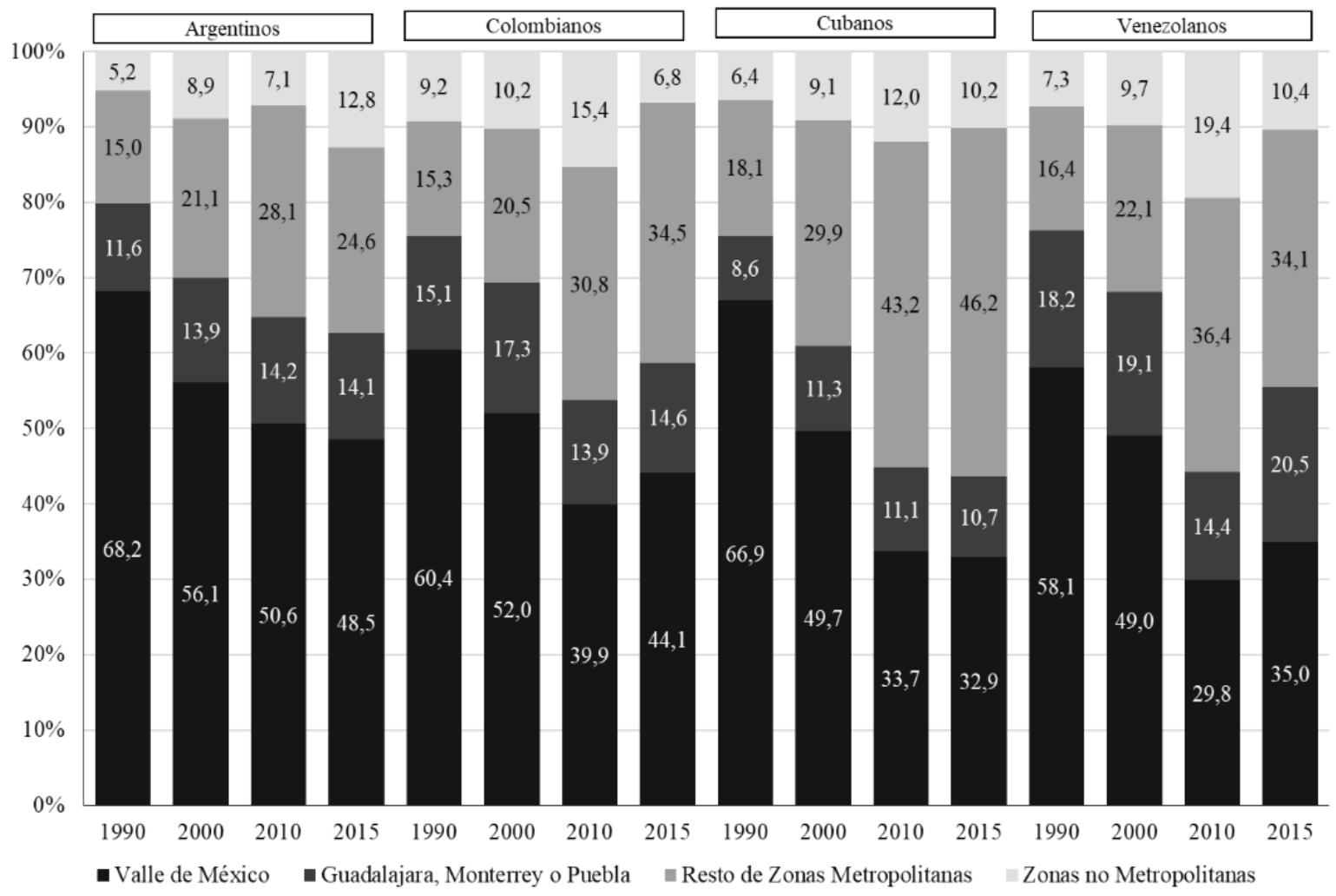

Nota: no se consideran aquellos cuyo lugar de nacimiento fue catalogado como "América", porque no se puede identificar si son de Estados Unidos o de América Latina.

Fuente: estimaciones propias con base en los Censos de Población 1990, 2000, 2010 y en la

Encuesta Intercensal 2015 (INEGI, s. f.-d). Delimitación de las zonas metropolitanas de México, 1990, 2000, 2010 y 2015. 


\section{Gráfico 4. Residencia de los inmigrantes según región de origen y área metropolitana (México: 1990-2015)}

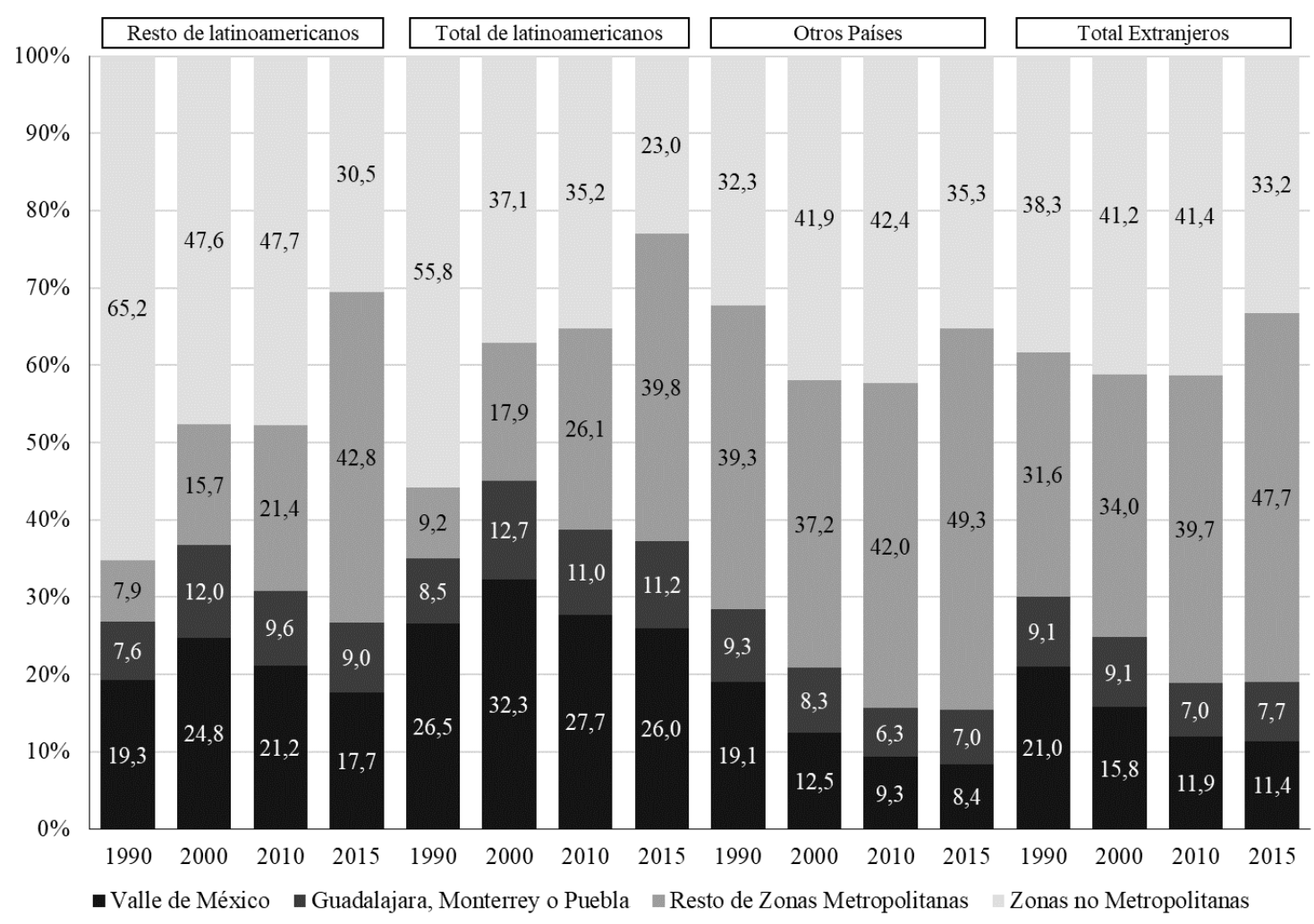

Nota: no se consideran aquellos cuyo lugar de nacimiento fue catalogado como "América", porque no se puede identificar si son de Estados Unidos o de América Latina.

Fuente: estimaciones propias con base en los Censos de Población 1990, 2000, 2010 y en la Encuesta Intercensal 2015 (INEGI, s. f.-d). Delimitación de las zonas metropolitanas de México, 1990, 2000, 2010 y 2015.

La mirada diacrónica (1990-2015) revela una clara tendencia a la redistribución espacial de los inmigrantes hacia otras áreas metropolitanas, coherente con las pautas de la urbanización en México (Garza, 2003). A principios de la década de 1990 más del $60 \%$ de los inmigrantes de estos cuatro países residía en la Zona Metropolitana del Valle de México; 25 años después, el porcentaje se redujo a una tercera parte, con la excepción de los argentinos.

\section{Inserción sociolaboral: aventajados pero desiguales}

$\mathrm{El}$ análisis de la inserción laboral de los inmigrantes latinoamericanos que emprendemos en este artículo reviste el interés de centrarse en extranjeros selectos en términos educativos, condición que les otorga ventajas indudables en el mercado de trabajo. Como queda en evidencia en la tabla 3, los inmigrantes de estos cuatro países superan a los mexicanos y al resto de los latinoamericanos en todos los indicadores contemplados: ingresos promedio, ramas de actividad, sector de ocupación (no manual o manual). Albergan también diferencias intergrupales importantes. 
Ya sea si se toman los ingresos promedio o su mediana, argentinos, cubanos, colombianos y venezolanos ganan al menos dos veces más que el resto de los latinoamericanos, y tres veces más que los mexicanos (tabla 3). Un vistazo a los rasgos de su inserción laboral permite entender tal disimilitud. En conjunto, más del $80 \%$ de los argentinos, cubanos, colombianos y venezolanos son trabajadores no manuales (y entre el 44 y el 56,8\%, profesionales y directivos), porcentaje que en el resto de los latinoamericanos y en los nacidos en México no excede el 45,1\%. En el mismo sentido, aun cuando todos los grupos de población se alojan de forma mayoritaria en el terciario, sector dominante de la economía mexicana desde mediados de 1990, es mucho mayor la presencia de argentinos, cubanos, colombianos y venezolanos en los ámbitos modernos (o altos) de dicho sector (servicios sociales y financieros, alrededor del 45,6\%) que la del resto de los latinoamericanos $(22,6 \%)$ y los mexicanos $(26,3 \%)$. En otras palabras, los inmigrantes de estos cuatro países se encuentran sobrerrepresentados en ámbitos del mercado laboral que gozan de mejores condiciones y requieren fuerza de trabajo calificada (García, 2012; García y Oliveira, 2001).

Con la finalidad de identificar los patrones de asociación existentes entre las distintas variables sociolaborales y los orígenes de los inmigrantes, aplicamos un análisis de correspondencias múltiple para el total de los latinoamericanos, lo que nos permite delinear a nuestros grupos de análisis en el conjunto de la inmigración regional. ${ }^{18}$ Las variables incluidas son: sector de ocupación (no manual o manual); rama de actividad (primario, secundario y tipo de terciario: alto o bajo); y un rango de ingreso laboral promedio (entre 10 mil y 20 mil pesos mexicanos). Como se observa en el gráfico 5, la primera dimensión del eje de coordenadas, que explica más del $90 \%$ de la varianza, discrimina a los inmigrantes según sean trabajadores manuales (sector en el que se ubica exclusivamente el resto de los latinoamericanos), o no manuales (valores negativos y positivos, respectivamente). La segunda dimensión, los separa por el sector o subsector de inserción en la economía: primario y secundario versus terciario moderno o alto (sociales, gobierno y finanzas) y tradicional o bajo (comercio, transporte y servicios diversos).

\footnotetext{
18 Por razones estadísticas excluimos a los mexicanos, ya que su gran volumen hubiera oscurecido las
} diferencias internas entre los latinoamericanos. 
Tabla 3. Indicadores sociolaborales por condición migratoria (región y país de origen, México, 2015)

\begin{tabular}{|c|c|c|c|c|c|c|c|c|c|}
\hline Indicadores sociolaborales (1) & Argentinos & Colombianos & Cubanos & Venezolanos & $\begin{array}{c}\text { Resto de } \\
\text { Latinoamericanos }\end{array}$ & Latinoamericanos & $\begin{array}{c}\text { Otros } \\
\text { Extranieros }\end{array}$ & $\begin{array}{c}\text { Total } \\
\text { Extranieros }\end{array}$ & $\begin{array}{l}\text { Población } \\
\text { Mexicana }\end{array}$ \\
\hline Población en edad de trabajar & 8.948 & 10.342 & 7.732 & 8.135 & 56.835 & 91.992 & 144.091 & 237.144 & 45.085 .410 \\
\hline Económicamente activos & 64,7 & 59,3 & 64,8 & 61,1 & 57,9 & 59,5 & 35,2 & 41,9 & 50,2 \\
\hline No económicamente activos & 34,8 & 40,3 & 35,2 & 38,4 & 41,9 & 40,3 & 64,4 & 57,8 & 49,4 \\
\hline Total & 99,6 & 99,6 & 100,0 & 99,5 & 99,8 & 99,8 & 99,7 & 99,7 & 99,6 \\
\hline \multicolumn{10}{|l|}{ Posición en el trabajo } \\
\hline Asalariados & 58,0 & 66,4 & 68,3 & 72,5 & 65,3 & 65,6 & 70,0 & 68,3 & 73,2 \\
\hline No asalariados & 40,8 & 33,1 & 30,5 & 27,4 & 33,2 & 33,2 & 28,3 & 30,2 & 25,6 \\
\hline Total (2) & 98,8 & 99,5 & 98,8 & 99,9 & 98,4 & 98,8 & 98,3 & 98,5 & 98,8 \\
\hline \multicolumn{10}{|l|}{ Rama de actividad económica } \\
\hline Primarias & -- & -- & -- & -- & 14,6 & 9,4 & 4,6 & 6,4 & 1,1 \\
\hline Secundarias & 12,5 & 13,6 & $6,3 *$ & 22,1 & 18,7 & 16,8 & 19,3 & 18,3 & 27,8 \\
\hline Terciarias (subtotal) & 82,5 & 83,7 & 90,0 & 74,3 & 65,1 & 71,8 & 73,0 & 72,5 & 71,1 \\
\hline $\begin{array}{l}\text { Comercio, transporte y servicios diversos } \\
\text { (Terciario bajo) }\end{array}$ & 40,2 & 36,8 & 39,9 & 31,1 & 42,4 & 40,4 & 41,4 & 41,0 & 44,8 \\
\hline $\begin{array}{l}\text { Sociales, gobierno y financieros (Terciario } \\
\text { Alto) }\end{array}$ & 42,3 & 46,9 & 50,2 & 43,2 & 22,6 & 31,4 & 31,6 & 31,5 & 26,3 \\
\hline Total de ramas de actividad económica (2) & 95,0 & 97,4 & 96,3 & 96,4 & 98,3 & 97,9 & 96,9 & 97,3 & 100,00 \\
\hline \multicolumn{10}{|l|}{ Cateogrías ocupacionales } \\
\hline No manuales (subtotal) & 82,5 & 85,9 & 86,3 & 87,6 & 45,1 & 60,6 & 65,0 & 63,3 & 42,1 \\
\hline Profesionistas y directivos & 44,0 & 49,3 & 50,1 & 56,8 & 20,9 & 31,9 & 28,8 & 30,1 & 13,6 \\
\hline Otras ocupaciones no manuales & 38,5 & 36,6 & 36,2 & 30,8 & 24,3 & 28,6 & 36,1 & 33,2 & 28,5 \\
\hline Manuales & 15,5 & 13,6 & $13,1 *$ & $11,7^{*}$ & 54,0 & 38,6 & 33,4 & 35,4 & 57,9 \\
\hline Total (2) & 98,0 & 99,5 & 99,4 & 99,3 & 99,2 & 99,1 & 98,4 & 98,7 & 142,10 \\
\hline \multicolumn{10}{|l|}{ Promedio ingresos laborales (3) } \\
\hline Asalariados & $27.283,25$ & $24.329,16$ & $13.853,79$ & $23.047,47$ & $10.867,95$ & $15.084,00$ & $17.584,23$ & $16.607,45$ & $6.404,14$ \\
\hline No asalariados & $22.651,01$ & $15.357,38$ & $15.465,02$ & $22.188,89$ & $8.868,64$ & $12.587,00$ & $18.851,88$ & $16.067,47$ & $5.863,10$ \\
\hline Total & $25.388,77$ & $21.394,91$ & $14.305,94$ & $22.822,14$ & $10.185,10$ & $14.224,00$ & $17.949,02$ & $16.436,67$ & $6.483,00$ \\
\hline
\end{tabular}

Notas: (1) Los indicadores refieren a la población mayor de 12 años. Las estimaciones absolutas y relativas tienen límites de confianza al $90 \%$.

(2) La mayoría de los indicadores no suma $100 \%$, debido a que no se muestran los casos sin respuesta especificada.

(3) Cantidades en pesos mexicanos.

* Estimaciones a interpretar con precaución, debido a que su coeficiente de variación fue de entre 15 y $30 \%$.

-- Las estimaciones con coeficientes de variación superiores a $30 \%$ se omiten, pues la muestra arroja malas estimaciones.

Fuente: estimaciones propias con base en la Encuesta Intercensal 2015 (INEGI, s. f.-d) y Consejo Nacional de Población (CONAPO). 
Tres patrones de asociación se visualizan con nitidez: uno, integrado por el resto de los latinoamericanos, con salarios promedio inferiores a los 10 mil pesos, ocupaciones manuales e inserción en los sectores primario y secundario de la economía. Otro, que aglutina a colombianos y venezolanos, con ingresos elevados, presencia de profesionales y directivos (trabajadores no manuales altos) e inserción en los subsectores modernos de los servicios. Y un tercer grupo, algo más heterogéneo, en el que se encuentran los cubanos y los argentinos, con ingresos promedio entre 10 mil y 20 mil pesos, actividades no manuales y presencia en los sectores bajos de los servicios.

Hasta aquí, el análisis estadístico resulta consistente con los perfiles diferenciales de los inmigrantes previamente descritos. En el subuniverso del "resto de los latinoamericanos" tienen un peso importante los guatemaltecos, trabajadores manuales de baja calificación, con presencia en los sectores primario y secundario de la economía y de bajos ingresos. Este grupo se decanta de los cubanos, los argentinos, los colombianos y los venezolanos, quienes conforman dos patrones congruentes con el mayor nivel de escolaridad de los andinos, los más selectos de nuestra muestra, y su inserción laboral preferente en los subsectores altos del terciario (ver tabla 3 ).

Este primer análisis de correspondencias proporciona un contexto de referencia para profundizar en la heterogeneidad interna de los grupos de análisis. Replicamos el ejercicio estadístico restringiendo la observación al subuniverso de argentinos, cubanos, colombianos y venezolanos. En vista de que más del $80 \%$ de ellos son trabajadores no manuales, sustituimos dicha variable por la de posición en el trabajo (asalariada o no asalariada), en la cual poseen mayor variabilidad interna; y excluimos al sector primario, dada su nula importancia en esta subpoblación (ver tabla 3). Conservamos el sector secundario y la diferenciación entre subsectores altos (servicios sociales, gobierno y finanzas) y bajos (comercio, transporte y servicios diversos) de los servicios. Elevamos el rango de la variable de ingresos hasta el umbral de 20.000, en virtud de los mejores ingresos que gozan estos trabajadores. 
Gráfico 5. Análisis de correspondencias múltiple de la dimensión sociolaboral de los inmigrantes latinoamericanos (México, 2015)

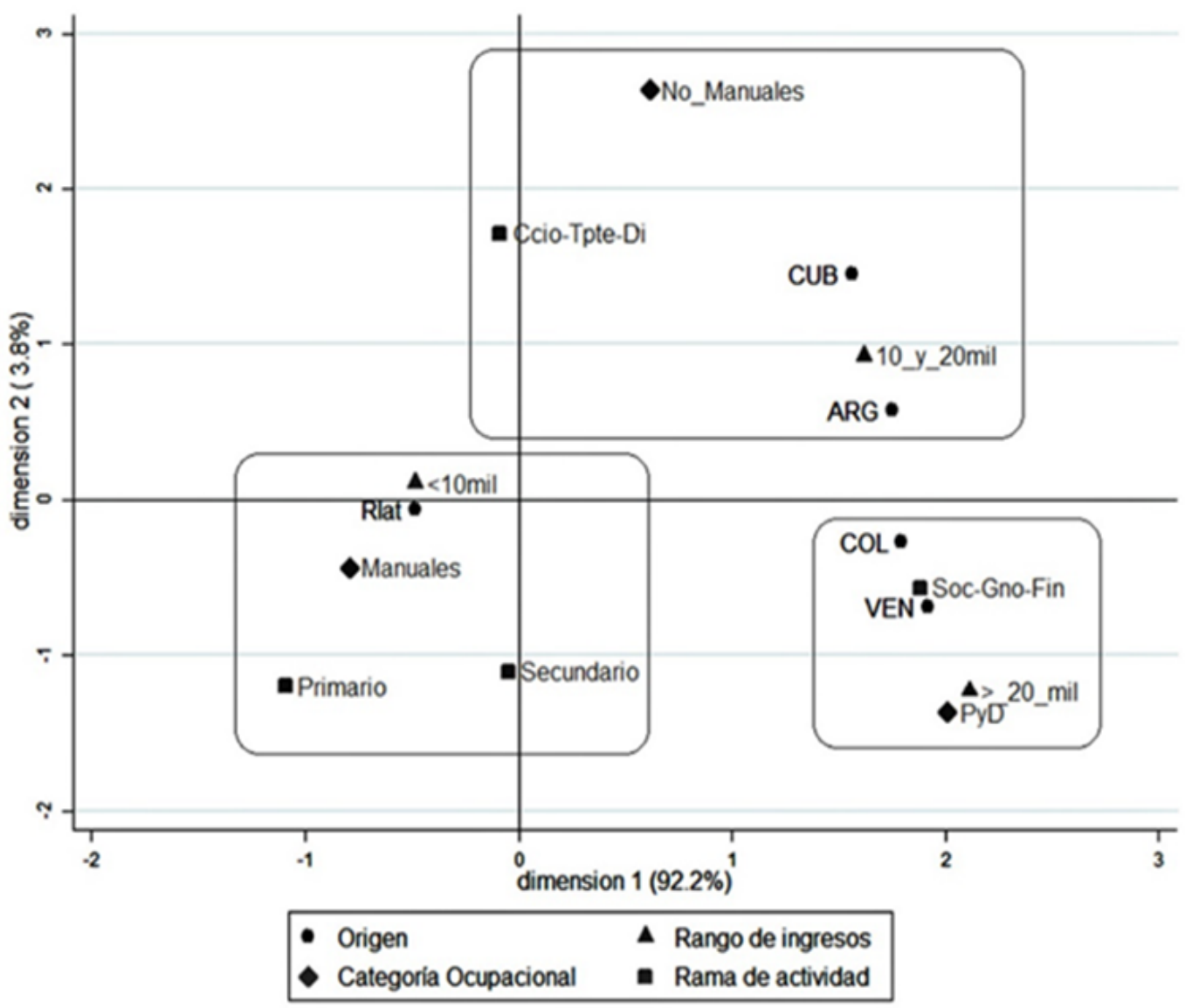

Fuente: elaboración propia con base en la Encuesta Intercensal 2015 (INEGI, s. f.-d). 


\section{Gráfico 6. Análisis de correspondencias múltiple de la dimensión sociolaboral de los inmigrantes latinoamericanos (países seleccionados, México, 2015)}

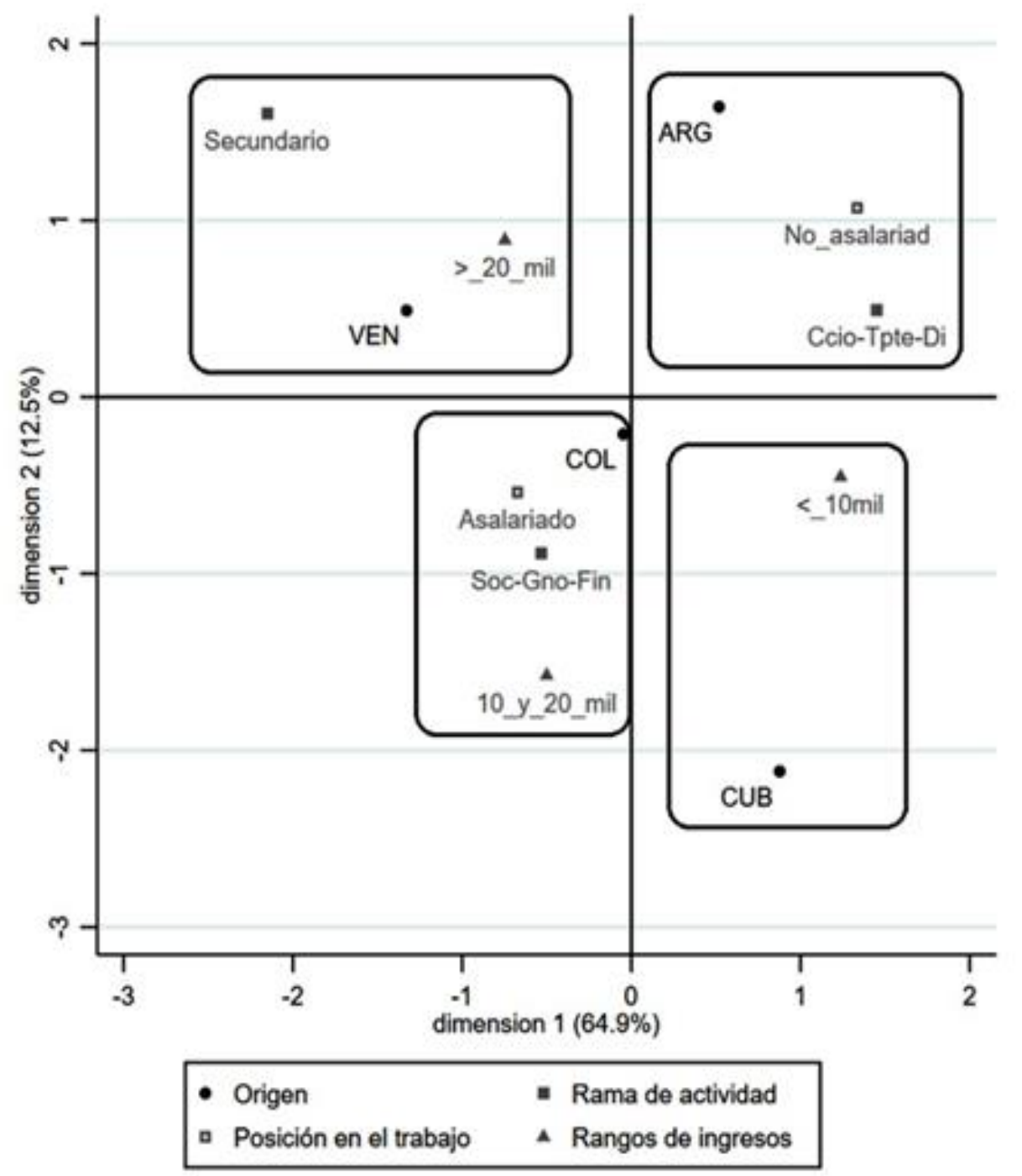

Fuente: elaboración propia con base en la Encuesta Intercensal 2015 (INEGI, s. f.-d).

La dimensión 1 del eje de coordenadas (gráfico 6), que agrupa al 64,9 \% de la varianza, discrimina a los cuatro colectivos en dos: los que se asocian más a una inserción no asalariada (argentinos y, bastante más lejos, los cubanos), o asalariada (venezolanos y colombianos). La segunda dimensión del cuadrante, $12,5 \%$ de la varianza, los separa según el nivel de ingresos promedio (por encima o por debajo de los 20 mil pesos). Del cruce entre ambas emergen cuatro patrones de asociación: uno, conformado por los argentinos, vinculados a actividades no asalariadas, inserción laboral en el comercio, los transportes y los servicios diversos (terciario bajo), pero con ingresos elevados.

Un segundo patrón, en el que figuran los venezolanos, con ingresos laborales igualmente altos, inserción en el sector secundario de la economía y presencia importante de 
profesionales y directivos. Los otros dos patrones identificados, conformados por colombianos y cubanos, gozan de una situación menos favorable, pues devengan ingresos inferiores al umbral de más de 20 mil pesos (principalmente los nacidos en la isla del Caribe). Mientras los colombianos, próximos al origen del eje de coordenadas, son asalariados alojados en los sectores modernos (o altos) del terciario, en tanto que los cubanos, muy distantes de los valores promedio, se asocian más a inserciones no asalariadas (como los argentinos), pero devengan los ingresos laborales más bajos de todos. Surge entonces la pregunta acerca de qué factores subyacen a estas diferencias en una población bastante homogénea en cuanto a sus niveles de escolaridad y el carácter principalmente no manual de su fuerza de trabajo. Para responderla emprendemos un tercer ejercicio estadístico multivariado.

\section{Determinantes del ingreso laboral}

El gráfico 7 recoge los coeficientes beta resultantes del ajuste de un modelo de regresión múltiple para el año 2015, cuya variable dependiente es el logaritmo del ingreso laboral. ${ }^{19}$ Las variables independientes se agrupan en cuatro: 1) individuales (edad -variable continua o métrica-; edad al cuadrado; escolaridad -años acumulados-; y sexo, variable de control); 2) sociales (país de origen: Argentina, Cuba, Colombia, Venezuela; y antigüedad de la migración: residencia de cinco años atrás); 3) laborales (posición en el trabajo: asalariada o no; sector de ocupación: manual o no manual; sector de actividad: primario, secundario y terciario, alto (servicios sociales, gobierno y servicios financieros) o bajo (comercio, transporte y servicios diversos); y 4) una variable socioespacial (residencia en la Zona Metropolitana del Valle de México, o no), aproximación indirecta a la heterogeneidad socioespacial de los mercados laborales. Los altos valores de la bondad de ajuste ( $\mathrm{R}$ cuadrada, 0,489, tabla A.3 del apéndice) indican que el modelo da cuenta de buena parte de la variabilidad de los datos. ${ }^{20}$

\footnotetext{
${ }^{19}$ Se ajustó un modelo de regresión lineal de corte transversal para el año 2015. La variable dependiente, el ingreso laboral, fue linealizada. El modelo se estimó por Mínimos Cuadrados Ordinarios y por Máxima Verosimilitud, y soportó los supuestos de multicolinealidad, normalidad y homocedasticidad.

${ }^{20}$ Todas las variables resultaron significativas al $p<0,05$, con excepción de dos cuya $p$ valor es inferior 0,10 (ser colombiano: 0,075, y ser cubano: 0,052).
} 


\section{Gráfico 7. Coeficientes de la regresión lineal múltiple del ingreso laboral de los inmigrantes latinoamericanos (México, 2015)}

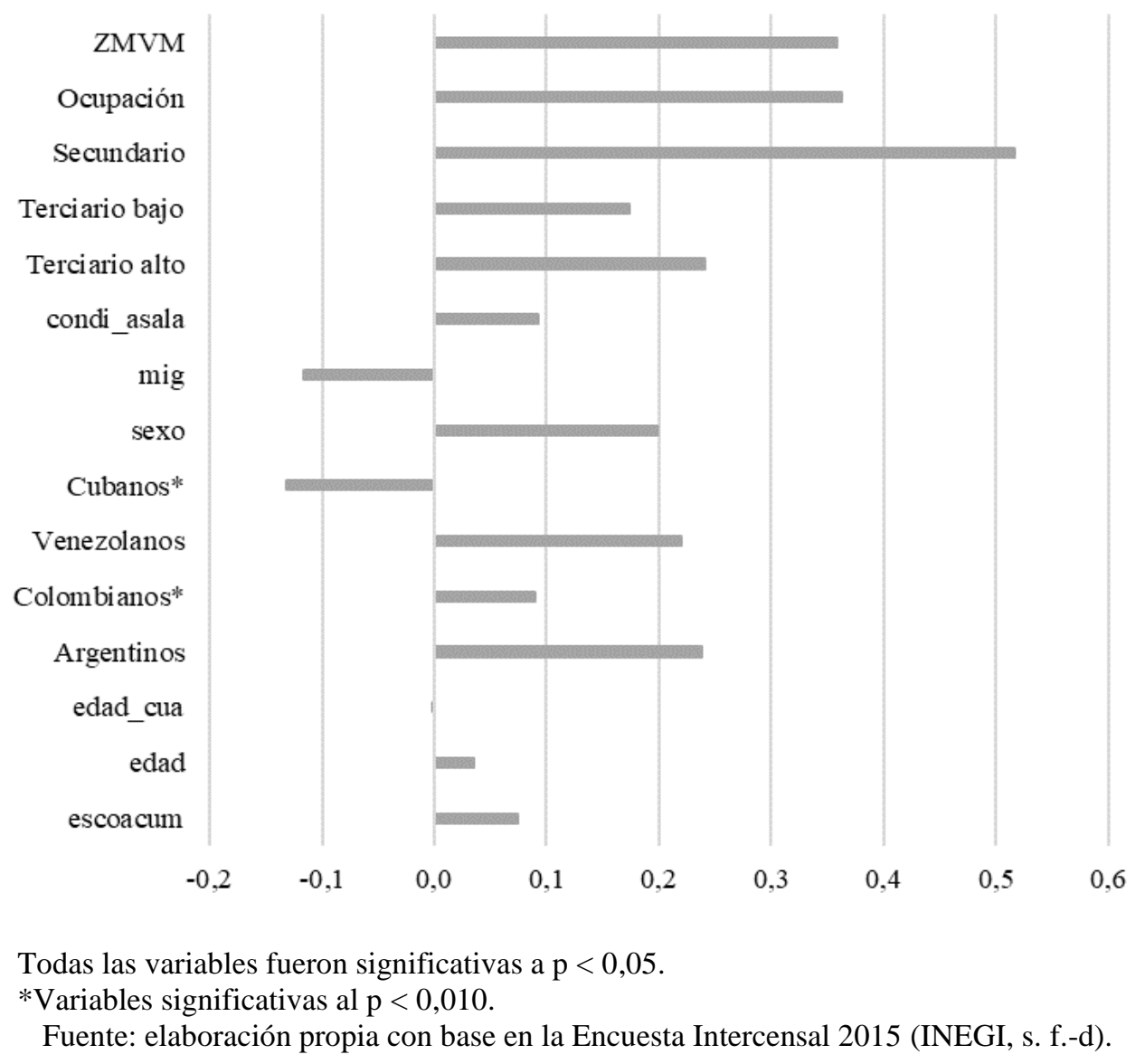

Como se recoge en el gráfico 7, son las variables laborales, seguidas de la socioespacial, las que más favorecen el incremento (en una unidad) de los ingresos (valores altos y positivos), una vez controladas las demás. Entre ellas, estar en el sector secundario de la economía es la de más fuerza explicativa, seguida de la condición de ser trabajador no manual y, con idéntico peso que esta última, el hecho de residir en la Zona Metropolitana del Valle de México. También, aunque con un impacto positivo menor, pertenecer a los subsectores altos del terciario (servicios sociales, financieros y gobierno).

Luego de las variables laborales y de la residencia en la Zona Metropolitana del Valle de México, son las sociodemográficas las de mayor capacidad explicativa. En coherencia con el análisis de correspondencias, la condición de ser nacional de Argentina o de Venezuela (un poco menos) impacta positivamente el logaritmo del ingreso. En el universo de los latinoamericanos, ser colombiano promueve un mejor ingreso laboral, pero de forma mucho más moderada, contrario a ser nativo de Cuba. Esta variable, junto al hecho de llevar residiendo más de cinco años en México (antigüedad de la migración), son las únicas que de facto reducen el ingreso, manteniendo fijo el efecto de las demás. En tal sentido, los resultados desmienten la importancia de la antigüedad de la migración para favorecer una 
mejor inserción laboral, realzando en cambio la diversidad de los mercados de trabajo (ubicación socioespacial) y del tipo de sector económico en el que se insertan los inmigrantes. Ubicarse en el sector secundario de la economía (en donde participan relativamente más los venezolanos) o trabajar en la Ciudad de México (donde se concentran sobre todo los argentinos), son las dos condiciones más favorables.

El sexo, una variable de control dada su conocida relevancia en el mercado de trabajo ${ }^{21}$ se comporta en el sentido esperado: ser hombre eleva en 0,20 unidades el ingreso. Por último, llama la atención el sentido positivo, pero leve de la escolaridad acumulada sobre el ingreso, lo que entendemos guarda relación con la alta selectividad educativa de la inmigración latinoamericana a México. El dato indica que antes que un elemento de heterogeneidad con un fuerte impacto en las condiciones laborales, como suele suceder en muchos estudios del mercado de trabajo, la escolaridad constituye un aspecto de relativa homogeneidad en este subuniverso, que poco contribuye a elevar el ingreso.

En suma, el análisis estadístico revela que, aunque selectos y con posiciones relativamente aventajadas en el mercado de trabajo (máxime si se comparan con los nacidos en México y en el resto de América Latina), prevalecen desigualdades laborales importantes en este grupo de inmigrantes respecto de las cuales es necesario profundizar.

\section{Conclusiones}

El ejercicio analítico emprendido en este artículo se propuso profundizar en la heterogeneidad (sociodemográfica y sociolaboral) de la inmigración latinoamericana reciente a México (1990-2015) para destacar el papel del país en la dinámica migratoria intrarregional, y examinar los rasgos diferenciales de la inserción laboral de estos inmigrantes, un aspecto poco abordado en la investigación regional (CEPAL y OIT, 2017).

Tres son las subregiones que nutren la inmigración latinoamericana reciente al país: la Andina (colombianos y venezolanos), el Cono Sur (argentinos) y el Caribe (cubanos). Los nacidos en América Latina (fuera de Centroamérica) sobresalen por su alta escolaridad y el predominio de mujeres. Al indagar en la diversidad interna de los primeros cuatro grupos de inmigración en 2015 (colombianos, venezolanos, argentinos y cubanos), emergieron diferencias en el grado de selectividad en favor de los más recientes (colombianos y venezolanos); y de feminización, pues en algunos colectivos predominan los hombres (argentinos y cubanos). La alta selectividad educativa de estos inmigrantes les otorga prerrogativas considerables en el mercado de trabajo, tanto respecto del resto de los latinoamericanos como de los mexicanos mismos.

\footnotetext{
${ }^{21}$ Contemplar las diferencias por sexo hubiera acarreado problemas muestrales, debido a la menor participación económica femenina.
} 
Sin embargo, existen notables desigualdades en su universo -medidas según el ingreso laboral- que denotan ventajas para unos (argentinos y venezolanos) y desventajas relativas para otros (colombianos y cubanos), que no guardan relación con la antigüedad de la migración, como postulaba la primera hipótesis de investigación. Venezolanos y argentinos se ubican en las antípodas respecto de los cubanos en cuanto al ingreso laboral, a pesar de la centenaria presencia de los caribeños en el país; los colombianos, en cambio, se sitúan en una posición intermedia. La relativa novedad y celeridad de la inmigración venezolana no impide que sus nacionales devenguen los mejores ingresos laborales, después de los argentinos, una vez controladas las demás variables independientes. Los cubanos son los peores retribuidos en el mercado de trabajo, aun cuando tengan esencialmente los mismos rasgos sociodemográficos y sociolaborales (trabajadores no manuales) que los demás.

El ejercicio estadístico multivariado revela que las desigualdades en los ingresos se explican ante todo por la inserción sociolaboral, dado que la escolaridad no es una variable de alto poder explicativo en un subuniverso tan selecto como este. Son los sectores de inserción económica (secundario, versus terciario alto o bajo) y la heterogeneidad (socioespacial) de los mercados laborales del país (Ciudad de México o resto metropolitano), los que permiten entender las diferencias encontradas, aspecto que otorga respaldo a la segunda hipótesis de investigación. Aun cuando los venezolanos están relativamente dispersos territorialmente, son los que exhiben una mayor participación relativa en el sector secundario, el que más favorece el incremento de los ingresos. Hipotetizamos que parte de esta inserción tiene lugar en la industria petrolera de la región económico funcional de Villahermosa, un sector laboral privilegiado. En contraste, la concentración relativa de los cubanos en los mercados de trabajo fuera de la Ciudad de México no va de la mano de mejores ingresos laborales. Para despejar esta incógnita sería necesario ahondar en la especificidad de los mercados trabajo locales en los que participan fuera de la metrópoli principal (Yucatán, Veracruz y otras áreas metropolitanas de menor tamaño).

Dos de los aspectos a los que este trabajo espera contribuir son: realzar el lugar de México en la dinámica migratoria intrarregional; y profundizar en los perfiles socioeconómicos y las desigualdades laborales presentes en el selecto grupo de inmigrantes latinoamericanos que en años han hecho de México su lugar de vida y trabajo. 


\section{Referencias Bibliográficas}

Acosta, D., Blouin, C., y Freier, L. (2019). La emigración venezolana: Respuestas latinoamericanas. Fundación Carolina, (3), 1-29. DOI: 10.13140/RG.2.2.33921.71523

Aja Díaz, A., Rodríguez, M. O., Orosa Busutil, R. y Albizu-Campos, J. C. (2017). La migración internacional de cubanos. Escenarios actuales. Novedades en Población, 13(26), 40-57.

Belot, M., y Hatton, T. (2008). Inmigrant Selection in the OECD. Centre for Economic Policy Research, 571, 1-38.

Bermúdez, R. (2019). Migración internacional calificada por razones de estudio: Colombianas en México. Ciudad de México: El Colegio de Mexico.

Borjas, G. J. (1987). Self-Selection and the Earnings of Migrations. National Bureau of Economic Research, 2248, 531-553.

Browning, H. L. y Feindt, W. (1969). Selectividad de migrantes a una Metrópoli en un país en desarrollo: Estudio de un caso mexicano. Demografía y Economía, 3(2), 186-200.

Cancio, W. (5 de enero de 2015). EEUU preocupado por aumento de balseros; 890 cubanos se lanzaron al mar desde octubre. caféfuerte. Recuperado de https://www.cafefuerte.com/?s=EEUU+preocupado+por+aumento+de+balseros.

Carrillo Flores, A. (1979). El asilo político en México. Jurídica, (1), 109-111.

Castillo, M. Á. y Olivera, M. V. (2010). Los inmigrantes guatemaltecos en México: Antecedentes históricos y situación actual. En E. Rodríguez Chávez (ed.), Extranjeros en México: continuidades y nuevas oportunidades (pp. 237-273). Ciudad de México: Instituto Nacional de Migración

CEPAL y OIT. (2017). Coyuntura Laboral en América Latina y el Caribe: La inmigración laboral en América Latina. Santiago: CEPAL/OIT.

Delgado Linero, M. G. (2019). Inserción ocupacional y trayectoria laboral de personas venezolanas en México y Estados Unidos: Profesionales del sector petrolero en Villahermosa y Houston (Tesis del programa de doctorado en Estudios de Migración). El Colegio de la Frontera Norte, Tijuana, Baja California. Recuperado de https://www.colef.mx/posgrado/tesis/20161353/

Diario Oficial de la Federación (DOF). Ley de Migración de los Estados Unidos Mexicanos, 13 de marzo de 1926. México. Recuperado de https://www.dof.gob.mx/nota_to_imagen_fs.php?codnota=4474652\&fecha=13/03/1 926\&cod_diario $=189617$ 
Diario Oficial de la Federación (DOF). Ley de Migración de los Estados Unidos Mexicanos, 30 de agosto de 1930. México. Recuperado de http://www.dof.gob.mx/nota_to_imagen_fs.php?codnota=4482378\&fecha=30/08/19 30\&cod_diario $=190188$

Diario Oficial de la Federación (DOF). Ley General de Población, 7 de enero de 1974. México. Recuperado de https://www.dof.gob.mx/nota_to_imagen_fs.php?codnota $=4655155 \&$ fecha $=07 / 01 / 1$ 974\&cod_diario $=200423$

Docquier, F., \& Marfouk, A. (2006). International Migration, Remittances and The Brain Drain. En Ç. Özden \& M. Schiff (Eds.), International Migration by Educational Attainment (1990-2000) (pp. 151-200). Washington, D.C: The World Bank and Palgrave Macmillan.

Durand, J. (2020). Migrantes desarraigados, Mesoamérica laboratorio migrante. En T. Botega, D. Dutra e I. Cunha (eds.), Movilidad en la frontera: Tijuana como espacio de (re)construcción de la vida (pp. 19-70). Brasília: CSEM.

Esteban, F. O. (2003). Dinámica migratoria argentina: inmigración y exilios. América Latina Hoy, 34, 15-34.

Fernández-Huertas, J. (2011). New evidence on Emigrant Selection. The Review of Economics and Statistics, 93(1), 72-96.

Freitez, A. (2019). Crisis humanitaria y migración forzada desde Venezuela. En L. Gandini, V. Pietro y F. Lozano (eds.), Crisis y migración de población venezolana. Entre la desprotección y la seguridad jurídica en Latinoamérica (pp. 33-58). México: UNAM.

Gandini, L. (2015). ¿Escapando de la crisis? Un estudio comparativo de trayectorias laborales de migrantes argentinos en la Ciudad de México y Madrid. México: Universidad Nacional Autónoma de México.

Gandini, L., Pietro, V. y Lozano, F. (eds.). (2019). Crisis y migracion de población venezolana. Entre la desprotección y la seguridad jurídica en Latinoamérica. México: UNAM.

Gandini, L., Prieto, V. y Lozano, F. (eds.). (2019). El éxodo venezolano: migración en contextos de crisis y respuestas de los países latinoamericanos. En L. Gandini, V. Prieto y F. Lozano Ascencio, Crisis y migracion de población venezolana. Entre la desprotección y la seguridad jurídica en Latinoamérica. México: UNAM.

García, B. (2012). La precarización laboral y el desempleo en México (2000-2009). En E. de la Garza (ed.), La situación del trabajo en México, 2012, el trabajo en la crisis (pp. 91-118). México: Universidad Autónoma Metropolitana Iztapalapa/Plaza y Valdés Editores. 
García, B. y Oliveira, O. (2001). Heterogeneidad laboral y calidad de los empleos en las principales áreas urbanas de México. Revista latinoamericana de estudios del trabajo, 7(14), 145-164.

Garza, G. (2003). La urbanización de México en el siglo XX (1 ${ }^{\text {a }}$, reimpresión ed.). México D.F.: El Colegio de Mexico. DOI: 10.2307/j.ctv6mtctk.1

González, M., Recaño, J. y López, A. (2020). Selectividad migratoria y acumulación regional del capital humano cualificado en España. Investigaciones Regionales, 47(2), 113133.

González-Murphy, L. V. y Koslowski, R. (2011). Entendiendo el cambio a las leyes de inmigración de México. Migration and Migrants. [Publicación en línea de Wilson Center], 1-48.

Herrera Barreda, M. del S. (2010). Un siglo de inmigración cubana en México, 1860-1959. En E. Rodríguez Chávez (ed.), Extranjeros en México. Continuidades y aproximaciones (pp. 275-306). México: Instituto Nacional de Migración.

Instituto Nacional de Estadística y Geografía (INEGI). (s. f.-a). XI Censo General de $\begin{array}{lllll}\text { Población } & \mathrm{y} & \text { Vivienda } & \text { Recuperado }\end{array}$ https://www.inegi.org.mx/programas/ccpv/1990/

Instituto Nacional de Estadística y Geografía (INEGI). (s. f.-b). XII Censo General de Población y Vivienda 2000. INEGI [sitio web]. Recuperado de https://www.inegi.org.mx/programas/ccpv/2000/\#Tabulados.

Instituto Nacional de Estadística y Geografía (INEGI). (s.f.-c). Censo de Población y Vivienda 2010. INEGI [sitio web]. Recuperado de https://www.inegi.org.mx/programas/ccpv/2010/\#Tabulados

Instituto Nacional de Estadística y Geografía (INEGI). (s.f.-d). Encuesta Intercensal 2015. INEGI [sitio web]. Recuperado de https://www.inegi.org.mx/programas/intercensal/2015/\#Microdatos

Jiménez Chaves, L. F. (2018). La inmigración laboral latinoamericana a las ciudades de México, Monterrey y Guadalajara, 1990-2015. (Tesis para optar a la maestría en Población y Desarrollo). Facultad Latinoamericana de Ciencias Sociales, México.

Leiva, S., Mansilla, M. A. y Comelin, A. (2017). Condiciones laborales de migrantes bolivianas que realizan trabajo de cuidado en Iquique. Sí Somos Americanos. Revista de Estudios Transfronterizos, 17(1), 11-37.

Mackenzie, D. y Rapoport, H. (2010). Self-selection patterns in Mexico-U.S. Migration: The role of migration networks. The Review of Economics and Statistics, 92(4), 811-821. 
Martínez, J., Cano, V. y Soffia, M. (2014). Tendencias y patrones de la migración latinoamericana y caribeña hacia 2010 y desafíos para una agenda regional. Serie Población y Desarrollo No 109. Santiago: CEPAL-Naciones Unidas.

Martínez, L. y Bobes, V. C. (2010). La inmigración cubana actual en México. En E. Rodríguez Chávez (ed.), Extranjeros en México. Continuidades y aproximaciones (pp. 307-330). México: Instituto Nacional de Migración.

Martínez Pérez, L. (2016). Características sociodemográficas, laborales y familiares de los cubanos censados en México en los años 2000 y 2010. En Cubanos en México: orígenes, tipologías y trayectorias migratorias (Primera, pp. 121-170). México D.F.: FLACSO México.

Martínez Pizarro, J. y Orrego Rivera, C. (2016). Nuevas tendencias y dinámicas migratorias en América Latina y el Caribe. Santiago: CEPAL-Naciones Unidas.

Merchan Rojas, L. y Merchan Rojas, Y. (2019). Perspectivas generales sobre la comunidad colombiana en México. En A. M. P. Pardo y C. A. A. D. Dávila Cervantes (eds.), Más allá de la emigración. Presencia de la población extranjera residente en México (pp. 213-230). México: Instituto de Gerografía, UNAM.

México. Leyes, decretos. (1893). Ley sobre extranjería y naturalización. En Código de colonización y terrenos baldíos de la República mexicana (pp. 1038-1050). México: Oficina Tip. de la Secretaría de Fomento. Recuperado de http://cd.dgb.uanl.mx/handle/201504211/13542

Naciones Unidas. (2015). World Population Prospects. Key Findings and Advance Tables. Nueva York: Departament of Economic and Social Affairs, Population Division.

Neira, F. (2010). Los inmigrantes colombianos en México: una caracterización sociodemográfica. En E. Rodríguez Chávez y M. del S. Herrera, Extranjeros en México. Continuidades y aproximaciones (pp. 307-330). México: Instituto Nacional de Migración.

OIM. (2019). Tendencias migratorias en las Américas. Informe Migratorio Sudamericano, octubre. Oficina Regional de la OIM para América del Sur.

Palma Mora, M. (2006). De tierras extrañas. Un estudio sobre la inmigración en México 1950-1990. México: INAH, Instituo Nacional de Migración y DGE.

Pederzini, C., Ruismena, F., Masferrer, C. y Molina, N. (2015). Tres décadas de migración desde el triángulo norte centroamericano: un panorama histórico y demográfico. Policy Bried Series Población, México: CIESAS. 1-34 
Polo Alvis, S. y Serrano López, E. (2019). La diáspora silenciosa: estudios sobre la tercera ola de migraciones colombianas al exterior (2005-2015). Desafíos, 31(1), 311-346. DOI: 10.12804/revistas.urosario.edu.co/desafios/a.6129

Ramírez Pérez, L. (2019). Transnacionalismo migrante en condición de Estados de origen con régimen autoritario: El caso de los cubanos en México (Tesis para optar al grado de doctor de Investigación en Ciencias Sociales). Facultad Latinoamericana de Ciencias Sociales, Sede Académica de México, México.

Ramírez, C., Zuluaga, M. y Perilla, C. (2010). Perfil migratorio de Colombia. Bogotá: Organización Internacional para las Migraciones (OIM).

Ratha, D., y Shaw, W. (2007). South-South Migration and Remittances. World Bank Working Paper $N^{\circ}$ 102. Washington, D.C.: The World Bank. DOI: 10.1596/978-0-8213-70728

Rodríguez Chávez, E. (2010). La inmigración en México a inicios del siglo XXI. En E. Rodríguez Chávez (ed.), Extranjeros en México: continuidades y nuevas aproximaciones. ( $1^{\mathrm{a}}$ ed., pp. 89-132). Mexico D.F.: Instituto Nacional de Migración, Centro de Estudios Migratorios.

Salazar Anaya, D. (2010). Las cuentas de los sueños. La presencia extranjera en México a través de las estadísticas nacionales, 1880-1914. México: Instituto Nacional de Migración, Centro de Estudios Migratorios.

Secretaría de Relaciones Exteriores. Gobierno de México (s. f.). México suprime el requisito de visa a nacionales del Perú. [En línea]. Secretaría de Relaciones Exteriores. Gobierno de México [sitio web]. Recuperado de https://embamex.sre.gob.mx/peru/index.php/sconsulares/visas\#: :text=Se\%20elimi na\%20la\%20visa\%20para,relaciones\%20entre\%20Per\%C3\%BA\%20y\%20M\%C3 $\%$ A9xico).

Selee, A., Bolter, J., Muñoz-Pogossian, B. y Hazán, M. (enero, 2019). Creatividad dentro de la crisis: opciones legales para inmigrantes venezolanos en América Latina.. Policy Brief. [En línea] Migration Policy Institute [sitio web]. Recuperado de https://www.migrationpolicy.org/sites/default/files/publications/VenezuelansLegalP athwaysBrief-Spanish-Final.pdf

Sjaastad, L. (1962). The cost and returns of human migration. Investment in Human Beings, pp. 80-93). Chicago: The Journal of Political Economy. Recuperado de http://www.nber.org/chapters/c13573

Solimano, A. (2003). Globalization and international migration: The Latin American experience. Cepal Review, 80, 53-63. 
Torres, A. (2011). La crisis colombiana de finales del siglo XX: ¿Un choque real o financiero? Perfil de Coyuntura Económica, (18), 79-96.

Vivas Peñalver, L. y Páez, T. (2017). The Venezuelan Diaspora, Another Impending Crisis? Washington, D.C.: Freedom House. DOI: 10.13140/RG.2.2.17819.87843

Yankelevich, P. (2010). El exilio argentino en México 1974-1983: un ejercicio de cuantificación. En E. Rodríguez (ed.), Extranjeros en México. Continuidades y Aproximaciones (pp. 367-393). México: Instituo Nacional de Migración.

Yankelevich, P. (2011). ¿Deseables o inconvenientes?: las fronteras de la extranjería en el México posrevolucionario. México: Bonilla Artigas Editores, INAH e Iberoamericana Vervuert. 


\section{Apéndice}

Tabla A.1. Porcentaje de población de 25 años y más con al menos educación secundaria (no necesariamente culminada, 2015)

\section{En el país de origen}

En México

54,6

50,2

Colombia

Cuba

84,8

68,9

98,3

96,6

97,1

98,9
Fuente: Programa de Desarrollo de la Naciones Unidas y Encuesta Intercensal 2015 (INEGI). http://hdr.undp.org/en/indicators/23806

\section{Diferencias}

43,7

46,4

12,3

30,0

\section{Tabla A.2. Inmigrantes latinoamericanos en México por condición de antigüedad} (2015)

\begin{tabular}{lcccccc}
\hline \multicolumn{1}{c}{ Indicadores } & Argentinos & Colombianos & Cubanos & Venezolanos $\begin{array}{c}\text { Resto de } \\
\text { Latinoamericanos }\end{array}$ Tatinoamericanos \\
\hline $\begin{array}{l}\text { Lugar de residencia 5 años atrás* } \\
\text { Antiguos }\end{array}$ & 73,0 & 60,6 & 80,2 & 59,9 & 75,7 & 72,7 \\
Recientes & 26,6 & 38,3 & 19,5 & 39,5 & 23,8 & 26,7 \\
Total & 99,6 & 98,8 & 99,7 & 99,4 & 99,4 & 99,4 \\
\hline
\end{tabular}

*Los indicadores de lugar de residencia cinco años atrás y escolaridad se refieren a los mayores a 5 y 15 años, respectivamente.

Fuente: estimaciones propias con base en la Encuesta Intercensal 2015 (INEGI) y Consejo Nacional de Población (CONAPO). 
Tabla A.3. Modelo de regresión múltiple del ingreso laboral de los inmigrantes latinoamericanos (México, 2015)

\begin{tabular}{|c|c|c|c|c|c|c|}
\hline \multirow{2}{*}{$\begin{array}{l}\text { Variable independiente } \\
\text { Escolaridad acumulada }\end{array}$} & \multirow{2}{*}{$\begin{array}{c}\begin{array}{c}\text { Coeficiente } \\
\text { Beta }\end{array} \\
0,07 \\
\end{array}$} & \multirow{2}{*}{$\begin{array}{c}\begin{array}{c}\text { Error } \\
\text { estándar }\end{array} \\
0,00 \\
\end{array}$} & \multirow{2}{*}{$\begin{array}{c}\mathbf{t} \\
21,89 \\
\end{array}$} & \multirow{2}{*}{$\begin{array}{c}\mathbf{P}>\mathbf{t} \\
0 \\
0\end{array}$} & \multicolumn{2}{|c|}{$\begin{array}{c}95 \% \\
\text { Intervalo de } \\
\text { confianza] }\end{array}$} \\
\hline & & & & & 0,07 & 0,08 \\
\hline Edad métrica & 0,04 & 0,01 & 6,74 & 0 & 0,02 & 0,05 \\
\hline Edad al cuadrado & 0,00 & 0,00 & $-5,73$ & 0 & 0,00 & 0,00 \\
\hline \multicolumn{7}{|l|}{ Latinoamericanos } \\
\hline Argentinos & 0,24 & 0,06 & 3,86 & 0 & 0,12 & 0,36 \\
\hline Colombianos* & 0,09 & 0,05 & 1,78 & 0,075 & $-0,01$ & 0,19 \\
\hline Venezolanos & 0,22 & 0,06 & 3,56 & 0 & 0,10 & 0,34 \\
\hline Cubanos* & $-0,13$ & 0,07 & $-1,94$ & 0,052 & $-0,26$ & 0,00 \\
\hline Resto de Latinoamericanos & -- & -- & -- & -- & -- & -- \\
\hline \multicolumn{7}{|l|}{ Sexo } \\
\hline Hombre & 0,20 & 0,03 & 6,63 & 0 & 0,14 & 0,26 \\
\hline Mujer & -- & -- & -- & -- & -- & -- \\
\hline \multicolumn{7}{|l|}{ Antigüedad de la migración } \\
\hline Antigua & $-0,12$ & 0,04 & $-3,21$ & 0,001 & $-0,19$ & $-0,04$ \\
\hline Reciente & -- & -- & -- & -- & $-{ }_{--}$ & -- \\
\hline \multicolumn{7}{|l|}{ Posición en el trabajo } \\
\hline Asalariado & 0,09 & 0,03 & 2,9 & 0,004 & 0,03 & 0,15 \\
\hline No asalariado & -- & -- & -- & -- & -- & -- \\
\hline \multicolumn{7}{|l|}{ Sector de la economía } \\
\hline Terciario Alto & 0,24 & 0,06 & 4,09 & 0 & 0,13 & 0,36 \\
\hline Terciario Bajo & 0,17 & 0,04 & 3,92 & 0 & 0,09 & 0,26 \\
\hline Secundario & 0,52 & 0,04 & 11,63 & 0 & 0,43 & 0,60 \\
\hline \multicolumn{7}{|l|}{ Sector de la ocupación } \\
\hline No manual & 0,36 & 0,04 & 8,69 & 0 & 0,28 & 0,44 \\
\hline Manual & -- & -- & -- & -- & -- & -- \\
\hline \multicolumn{7}{|l|}{ Residencia } \\
\hline $\begin{array}{l}\text { Zona Metropolitana del Valle } \\
\text { de México }\end{array}$ & 0,36 & 0,05 & 7,89 & 0 & 0,27 & 0,45 \\
\hline Otro lugar & -- & -- & -- & -- & -- & -- \\
\hline & 6,59 & 0,12 & 54,1 & 0 & 6,35 & 6,83 \\
\hline
\end{tabular}

Todas las variables fueron significativas a $\mathrm{p}<0,05$.

*Variables significativas al $\mathrm{p}<0,010$.

Valores del modelo: (1) número de observaciones: 9.210; (2) tamaño de la población: 72.938; (3) Prob > F: 0; (4) R-squared: 0,489.

Fuente: elaboración propia con base en la Encuesta Intercensal 2015 (INEGI). 